\title{
Paraburkholderia phytofirmans PsJN Protects Arabidopsis thaliana Against a Virulent Strain of Pseudomonas syringae Through the Activation of Induced Resistance
}

\author{
Tania Timmermann,, 1,3,4 Grace Armijo, ${ }^{2,3}$ Raúl Donoso, ${ }^{1,3,4}$ Aldo Seguel, ${ }^{2,3}$ Loreto Holuigue,,$^{2,3}$ and \\ Bernardo González ${ }^{1,3,4}$ \\ ${ }^{1}$ Laboratorio de Bioingeniería, Facultad de Ingeniería y Ciencias, Universidad Adolfo Ibáñez, Santiago, Chile; ${ }^{2}$ Departamento de \\ Genética Molecular y Microbiología, Facultad de Ciencias Biológicas, Pontificia Universidad Católica de Chile, Santiago, Chile; \\ ${ }^{3}$ Millennium Nucleus Center for Plant Systems and Synthetic Biology, Santiago, Chile; and ${ }^{4}$ Center of Applied Ecology and \\ Sustainability, Santiago, Chile
}

Accepted 19 January 2017.

\begin{abstract}
Paraburkholderia phytofirmans PsJN is a plant growth-promoting rhizobacterium (PGPR) that stimulates plant growth and improves tolerance to abiotic stresses. This study analyzed whether strain PsJN can reduce plant disease severity and proliferation of the virulent strain Pseudomonas syringae pv. tomato DC3000, in Arabidopsis plants, through the activation of induced resistance. Arabidopsis plants previously exposed to strain PsJN showed a reduction in disease severity and pathogen proliferation in leaves compared with noninoculated, infected plants. The plant defenserelated genes WRKY54, PRI, ERF1, and PDF1.2 demonstrated increased and more rapid expression in strain PsJN-treated plants compared with noninoculated, infected plants. Transcriptional analyses and functional analysis using signaling mutant plants suggested that resistance to infection by $\mathrm{DC} 3000$ in plants treated with strain PsJN involves salicylic acid-, jasmonate-, and ethylene-signaling pathways to activate defense genes. Additionally, activation occurs through a specific PGPR-host recognition, being a necessary metabolically active state of the bacterium to trigger the resistance in Arabidopsis, with a strain PsJNassociated molecular pattern only partially involved in the resistance response. This study provides the first report on the mechanism used by the PGPR P. phytofirmans PsJN to protect $A$. thaliana against a widespread virulent pathogenic bacterium.
\end{abstract}

Plants serve as ecological niches for diverse communities of microbes that work in concert with the plant to survive in a wide range of stressful environmental conditions (Coleman-Derr and Tringe 2014). Because roots deposit up to $40 \%$ of the plant's photosynthetically fixed carbon, microorganisms are predominantly hosted in the rhizosphere, representing this small zone around the roots, one of the most energy-rich habitats on earth (Bais et al. 2006). The rhizosphere is an important ecological niche in which several and complex plant-microbe interactions occur, which can be beneficial, neutral, or harmful to plants

Corresponding author: B. González; Telephone: +56-2-23311619; Fax: +56-2-23311906; E-mail: bernardo.gonzalez@uai.cl

*The $\boldsymbol{e}$-Xtra logo stands for "electronic extra" and indicates that four supplementary figures and two supplementary tables are published online.

@ 2017 The American Phytopathological Society
(Bais et al. 2006). Among the beneficial interactions are those involving plant growth-promoting rhizobacteria (PGPR) that colonize the rhizosphere of many plant species generating positive effects, such as increased plant growth, reduced susceptibility to diseases, and improved tolerance to abiotic stresses (Kloepper et al. 2004; Lugtenberg and Kamilova 2009; Pinedo et al. 2015; Poupin et al. 2013; van Loon 2007; Yang et al. 2009).

Diverse pathogens and pests can attack plants in complex natural environments. In agriculture, this leads to tremendous annual crop losses, representing a total value of over $€ 450$ billion worldwide (Vos et al. 2013). As such, elucidating the mechanisms of plant defense has become increasingly important. Two main levels of defense have been described (Jones and Dangl 2006). The first level, which involves recognition of potentially pathogenic microorganisms, is ensured by pattern recognition receptors that detect pathogen- or microbe-associated molecular patterns (PAMPs or MAMPs) (Schwessinger and Zipfel 2008). This recognition leads to a basal resistance called PAMP- or MAMPtriggered immunity (PTI or MTI), conferring low-level resistance to virulent pathogens (Jones and Dangl 2006). The second level is represented by a stronger and more specific resistance mechanism, the effector-triggered immunity (ETI), which involves a direct or indirect interaction between the product of a host resistance gene and its cognate pathogen-encoded effector protein (Jones and Dangl 2006; Xin and He 2013). Among ETI manifestations is the hypersensitive response, in which necrotic lesions develop at one or more sites of pathogen entry (Senthil-Kumar and Mysore 2013; Vlot et al. 2009). As a consequence of the ETI response, systemic acquired resistance (SAR) is activated. This is a long-lasting and broad-based resistance to infection by a wide variety of pathogens (Fu and Dong 2013; Ryals et al. 1996; Senthil-Kumar and Mysore 2013; Vlot et al. 2009). Reactive oxygen species and salicylic acid (SA) are essential for a successful PTI, ETI, and SAR responses (Herrera-Vásquez et al. 2015). Not only the hormone SA is important for the regulation of the plant immune responses but, also, jasmonic acid (JA) and ET hormones. JA and ET signaling can act synergistically to activate defense genes, mainly against necrotrophic pathogens (through the ET response factor [ERF] branch of the JA pathway) and against insect herbivory (through the MYC branch) (Pieterse et al. 2009). A fine-tuning crosstalk between SA and JA hormones plays a central role in the modulation of the plant immune signaling network (Caarls et al. 2015). Relative concentrations of each hormone, timing, and sequence 
of initiation of the SA and JA signaling are important to determine whether the interaction between both pathways will be antagonistic, neutral, or synergistic (Caarls et al. 2015; Koornneef et al. 2008; Liu et al. 2016; Mur et al. 2006; Pieterse et al. 2012).

Biological control using PGPR has been recognized as an attractive tool for plant disease management in modern agriculture and is considered as an alternative or a supplemental way to reduce the use of agrochemicals (Babalola 2010; Beneduzi et al. 2012; Bhattacharyya and Jha 2012; Compant et al. 2005a). PGPR have several mechanisms to fight pathogens, such as antagonism, production of antibiotics, signal interference (e.g., degradation of quorum-sensing $\mathrm{N}$-acyl homoserine lactones), competition for nutrients and niches, competition for ferric ions by siderophore production, and the activation of a plant defense system known as induced systemic resistance (ISR), in which plants are primed against pathogen attack (Haas and Défago 2005; Lugtenberg and Kamilova 2009; Weller et al. 2012). For many biological control agents, ISR has been recognized as the mechanism that, at least partly, explains the reduction in disease severity and incidence. ISR is a state of enhanced defensive capacity developed by a plant following colonization by PGPR or beneficial fungi (PGPF) (Naznin et al. 2014; Van der Ent et al. 2009; van Loon 2007; van Loon et al. 1998). In plants primed by ISR, defense responses are not activated directly but are accelerated upon pathogen or insect attack, resulting in enhanced resistance to the attacker (Van Wees et al. 2008). Fitness costs associated with induced defense arise from allocation and ecological costs. Therefore, the defense arsenal in primed plants remains dormant until pathogen infection, such that priming does not confer major fitness costs under pathogen-free conditions (van Hulten et al. 2006). The limited costs of the primed state are often compensated by the benefits in environments with pathogen or herbivore pressure (Vos et al. 2013).

A long and growing list of PGPR, principally Bacillus, Pseudomonas, and Serratia species, can elicit induced resistance and protect against a broad spectrum of pathogens in different plant species, including several crops, the model plant Arabidopsis, and even woody species (Choudhary and Johri 2009; De Vleesschauwer and Höfte 2009; Pineda et al. 2010). Remarkably, plant-protective responses by bacteria belonging to genus Burkholderia are less-studied at the molecular level, although this genus encompasses some of the more diverse and environmentally adaptable plant-associated bacteria able to establish a wide range of relationships with their hosts, including free-living in the rhizosphere as well as epiphytic, endophytic, obligate endosymbionts, and phytopathogens (Coenye and Vandamme 2003; Compant et al. 2008). In this context, Paraburkholderia phytofirmans PsJN (formerly Burkholderia [Sawana et al. 2014]) is a PGPR able to produce positive effects in horticultural crops such as tomato, potato, and grape (Ait Barka et al. 2006; Compant et al. 2005b; Kurepin et al. 2015; MiottoVilanova et al. 2016; Nowak et al. 1998; Sessitsch et al. 2005) but also in Arabidopsis (Pinedo et al. 2015; Poupin et al. 2013, 2016) and switchgrass (Wang et al. 2015). This bacterium harbors genetic characteristics that would allow efficient use of plant-related molecules as carbon and energy source, as well as a successful rhizospheric and endophytic colonization (Donoso et al. 2017; Mitter et al. 2013; Zúñiga et al. 2013). It has been also reported that this bacterium stimulates growth of inoculated plants and induces physiological changes enhancing plant adaptation to environmental stresses such as cold, salinity, and drought (Ait Barka et al. 2006; Fernández et al. 2012; Ledger et al. 2016; Naveed et al. 2014; Pinedo et al. 2015; Su et al. 2015; Theocharis et al. 2012). Nevertheless, little is known regarding the ability of $P$. phytofirmans PsJN to protect plants from pathogens. Only a couple of studies have reported biocontrol effects of strain PsJN in a whole plant in which its inoculation was shown to enhance resistance to the necrotrophic pathogen Botrytis cinerea in grapevine plants (Ait Barka et al. 2002; Miotto-Vilanova et al. 2016).

This study reports, for the first time, that $P$. phytofirmans PsJN acts as biocontrol agent of $A$. thaliana plants, reducing disease susceptibility against the virulent strain Pseudomonas syringae pv. tomato DC3000. The protection conferred by strain PsJN proceeds through the activation of induced resistance in the plant, activating SA-, JA- and ET-dependent signaling pathways. Furthermore, using strain PsJN derivatives or inactivated forms, it was determined that the recognition and, therefore, the protection provided by this PGPR strain in Arabidopsis is very specific and requires the bacterium to be metabolically active.

\section{RESULTS}

\section{$P$. phytofirmans PsJN protects $A$. thaliana plants against virulent Pseudomonas syringae $\mathrm{DC3000.}$}

In order to determine if strain PsJN protects its host against a phytopathogenic bacterium, infection assays in plants cocultivated with or without strain PsJN were performed with a virulent strain of Pseudomonas syringae pv. tomato DC3000 (Whalen et al. 1991; Xin and He 2013). To discriminate the effect of metabolically active bacteria from that of inactive or dead bacteria, a treatment with heat-killed bacterium (HKPsJN) was included. The results indicated that plants cocultivated with strain PsJN were resistant to the disease triggered by DC3000 during 28 days postinfection (dpi) (Fig. 1). The onset of symptoms, a gray-brown lesion and chlorosis, became evident from the third week, in control plants (21 dpi) (Fig. 1A). Additionally, disease severity determinations in infected plants yielded significant differences from day 21 onward among plants cocultivated with strain PsJN and plants cocultivated with HK-PsJN or noninoculated control plants (Fig. 1B).

DC3000 growth in plant leaves was monitored to determine whether the lack of symptom development correlated with restriction of pathogen multiplication. Results showed that plants cocultivated with strain PsJN controlled the pathogen population at its initial levels in all measured times (Fig. 1C). In contrast, in noninoculated plants and in plants cocultivated with HK-PsJN, the population of DC3000 was two orders of magnitude higher than in plants inoculated with metabolically active strain PsJN (Fig. 1C).

To determine if the protective response triggered by strain PsJN on Arabidopsis plants in early stages of its life cycle is sufficient to maintain the protection against the disease along the entire life cycle of the plant, a long-term assay was carried out. Results indicated that, after 56 dpi, 11-week-old plants cocultivated with strain PsJN exhibited a healthy phenotype (Fig. 2), with senescent leaves due its age (77 days after sowing [DAS]) (Pinedo et al. 2015; Poupin et al. 2013). In contrast, plants noninoculated with strain PsJN were completely chlorotic and dead (Fig. 2). Infected A. thaliana plants cocultivated with strain PsJN harbored a DC3000 population of $1 \times 10^{4} \mathrm{CFU}$ per milligram of fresh weight $(\mathrm{FW})$, the same order of magnitude of the CFU initially inoculated, even after $56 \mathrm{dpi}$. In the case of nonprotected, control plants, CFU of strain DC3000 could not be quantified, since the required normalization with plant FW was not possible due to extensive weakening of the tissues.

\section{Specific interaction between $A$. thaliana plants and $P$. phytofirmans PsJN is required for a protective effect against virulent Pseudomonas syringae $\mathrm{DC} 3000$.}

Most studies on biocontrol have interrogated only PGPR of interest and do not include non-PGPR strains as a control for specificity of the defense response. To study if the protective state triggered by strain PsJN on Arabidopsis was specific, tests 


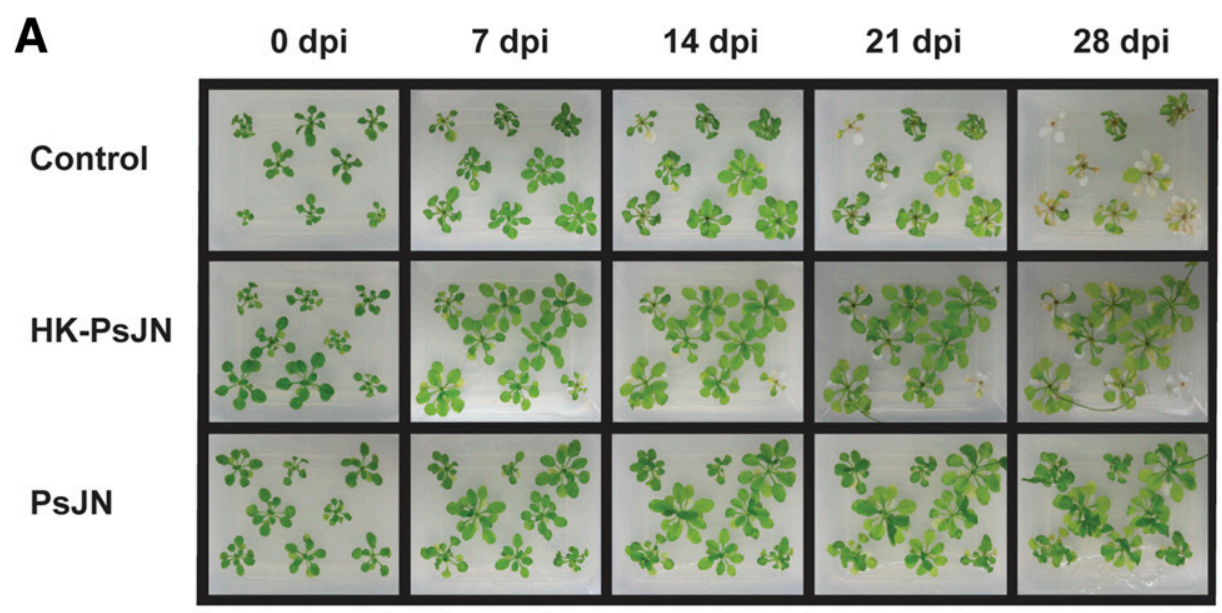

B

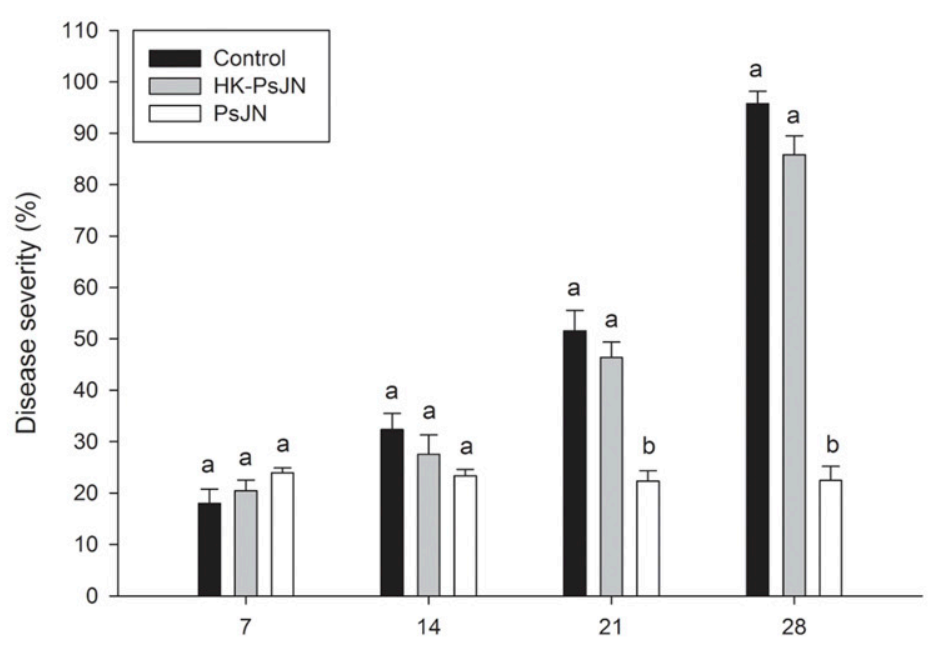

Days post infection (dpi)

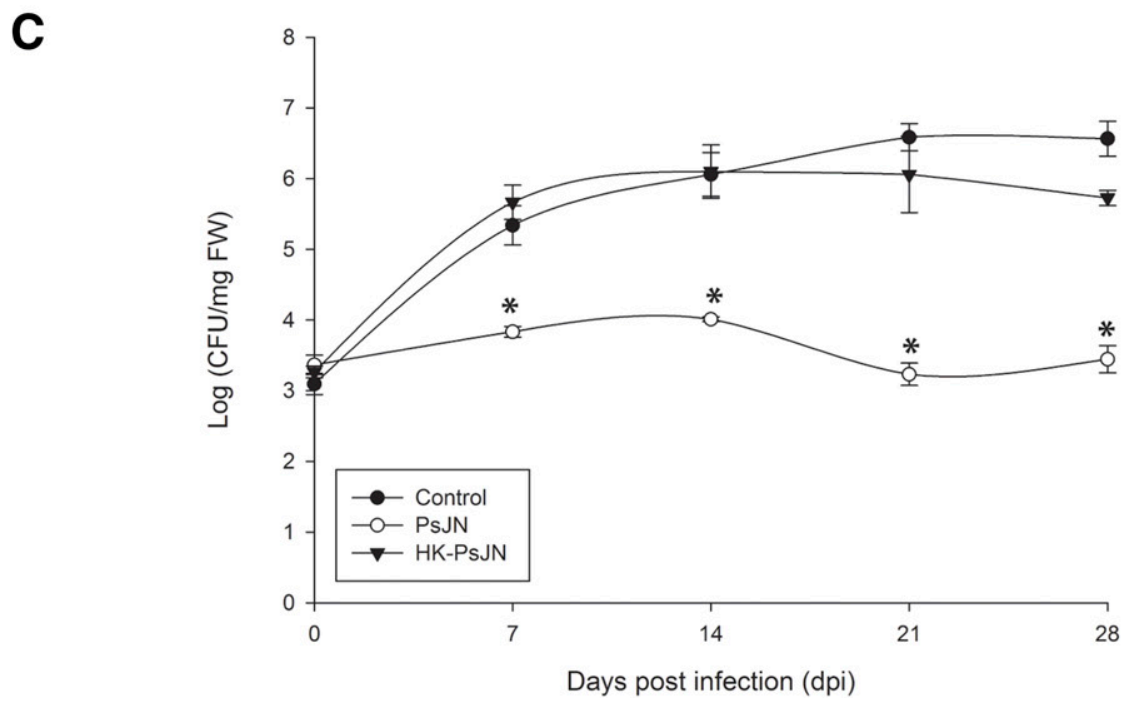

Fig. 1. Plant symptomatology, disease severity, and proliferation of virulent Pseudomonas syringae pv. tomato DC3000 in infected Arabidopsis thaliana plants cocultivated or not with Paraburkholderia phytofirmans PsJN. A, Representative photographs of Arabidopsis rosettes exposed to different treatments: plants cocultivated with P. phytofirmans PsJN, cocultivated with heat-killed bacteria (HK-PsJN), and noninoculated plants infected with a virulent strain of Pseudomonas syringae pv. tomato DC3000. Results were recorded at $0,7,14,21$, and 28 days after infection (dpi). B, Disease severity in strain PsJNinoculated, HK-PsJN-inoculated, and noninoculated Arabidopsis plants, after DC3000 infection. Disease severity was measured 7, 14, 21, and 28 dpi and the number of leaves per plant showing disease symptoms, where $0 \%$ means no leaves present symptoms and 100\% means that all leaves present symptoms. Each bar represents the average of at least eight individual plants and its standard error. Different letters on the bars indicate statistically significant differences among treatments (one-way analysis of variance [ANOVA], $P<0.05$; Tukey's test, $P<0.05$ ). C, Proliferation of virulent DC3000 (disease progression) in rosettes of Arabidopsis plants cocultivated or not with strain PsJN and HK-PsJN. Each point represents the log-transformed mean of eight individual plants (CFU per gram of leaf fresh weight) and its standard error. Asterisks indicate statistically significant differences between control and the other treatments in each time (one-way ANOVA, $P<0.05$; Tukey's test, $P<0.05$ ). Results are representative of four independent experiments. 
with two additional gram-negative bacteria belonging to phylum Proteobacteria were performed, using Escherichia coli $\mathrm{K} 12$ as a representative of a bacterium noninteracting with plants and Cupriavidus pinatubonensis JMP134, a non-PGPR belonging to the same family (Burkholderiaceae) of P. phytofirmans PsJN, previously reported to colonize Arabidopsis plants (Ledger et al. 2012). Results indicated that in the first two weeks after infection, plants cocultivated with strains K12 and JMP134 presented a transiently smaller population of D3000 than noninoculated plants, whereas plants cocultivated with strain PsJN exhibited a pathogen population significantly lower than the non-PGPR treatments (Fig. 3A). At $21 \mathrm{dpi}$, the proliferation of DC3000 was similar for noninoculated plants and plants inoculated with strains K12 and JMP134 and were three orders of magnitude higher than in plants inoculated with strain PsJN (Fig. 3A). The symptomatology observed 21 days after infection with these treatments (Fig. 3B) was in agreement with the effective control of DC3000 levels in the plant tissues.

\section{Metabolically active $P$. phytofirmans PsJN cells allowed a lower accumulation of reactive oxygen species in A. thaliana plants and were required for pathogen protection.}

To support the protective role of metabolically active strain PsJN, an additional assay measuring the phytopathogen population and symptomatology of disease in Arabidopsis plants using killed bacteria but conserving their cell integrity (K-PsJN) was performed. The K-PsJN treatment was also designed to determine if the protective response could be triggered by a MAMP of $P$. phytofirmans PsJN. Results showed that, in the first week after infection, plants cocultivated with K-PsJN exhibited a lower level of DC3000 proliferation than noninoculated plants, suggesting that MTI could be activated in these plants (Fig. 4A). However, from the second week after infection, plants cocultivated with K-PsJN presented the same level of DC3000 proliferation as noninoculated plants, which was significantly higher than the DC3000 proliferation of PsJN-treated plants (Fig. 4A). Moreover, the symptomatology of the disease 21 days after the infection event was consistent with the quantitative measurement of the population (Fig. 4B). As disease development induces oxidative stress, a histochemical assay to detect the reactive oxygen species superoxide anion $\left(\mathrm{O}_{2}^{-}\right)$ in Arabidopsis plants was carried out 21 days after DC3000

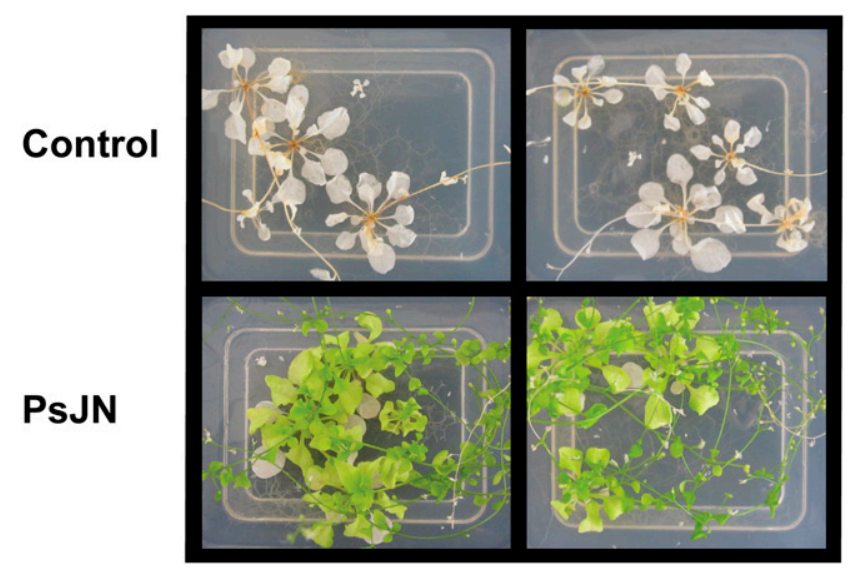

Fig. 2. Long-term protection of Arabidopsis thaliana plants cocultivated with Paraburkholderia phytofirmans PsJN. Two representative photographs of PsJN-treated and nontreated plants infected with the virulent strain of Pseudomonas syringae DC3000. Photos were taken 77 days after sowing and 56 days after infection. At the end of the plant life cycle, strain PsJNtreated plants show suppressed disease symptoms and, conversely, noninoculated plants present complete chlorotic and dead tissues. infection. The results indicated that plants cocultivated with metabolically active strain PsJN accumulated less $\mathrm{O}_{2}^{-}$(visualized as a blue precipitate) than control and K-PsJN cocultivated plants (Fig. 4C).

\section{$P$. phytofirmans PsJN induces transcriptional changes in $\mathrm{SA}$ and $\mathrm{JA} / \mathrm{ET}$ responsive-defense genes \\ in A. thaliana plants infected \\ with virulent Pseudomonas syringae DC3000.}

To better understand the defense mechanisms involved in Arabidopsis protection mediated by $P$. phytofirmans PsJN against Pseudomonas syringae DC3000, the transcriptional profiles of well-characterized defense-related genes of $A$. thaliana were studied. The expression pattern of PATHOGENESISRELATED GENE 1 (PRI; AT2G14610), a key marker of the SA signaling pathway, and PLANT DEFENSIN 1.2 (PDF 1.2; AT5G44420), a key marker of the JA/ET signaling pathways, were measured by analyzing mRNA accumulation in whole noninoculated plants (control) and in plants cocultivated with strain PsJN before and after DC3000 infection (0 and 1, 6, and $24 \mathrm{~h}$, respectively). $P R 1$ belongs to a group of genes that code for proteins with antimicrobial activity (van Loon et al. 2006) and is the best-characterized and most common marker for the SA signaling pathway (Vlot et al. 2009). A molecular cascade relying on salicylate-dependent signals to $P R 1$ via NPR1, WRKY, and TGA transcription factors has been well established (Eulgem 2005; Vlot et al. 2009). Results indicated that PRl gene was significantly up-regulated in plants cocultivated with $P$. phytofirmans PsJN 1, 6, and $24 \mathrm{~h}$ after DC3000 infection (Fig. 5). The expression patterns of two other important genes of the SA signaling pathway, ISOCHORISMATE SYNTHASE 1 (ICS1; AT1G74710) and the transcription factor WRKY54 (AT2G40750), were analyzed as well. ICS1 was up-regulated in Arabidopsis plants cocultivated with strain PsJN before infection (time $0 \mathrm{~h}$ ) and WRKY54 was down-regulated at the same time. Nevertheless, WRKY54 was up-regulated 1 and $24 \mathrm{~h}$ after infection in strain PsJN-treated plants (Supplementary Fig. S1A).

Because crosstalk between the defense hormones SA and JA plays a central role in the modulation of the plant immune signaling network (Pieterse et al. 2009), the study of the PDF1.2 expression pattern was also addressed. PDF1.2 encodes a plant defensin with antimicrobial properties and is activated by the transcription factor ERF1 (Penninckx et al. 1996), which is an important node of convergence of JA and ET signaling pathways (Lorenzo et al. 2003; Pieterse et al. 2009). Results of quantitative reverse transcription-polymerase chain reaction (qRT-PCR) indicated that $P D F 1.2$ was significantly up-regulated in plants cocultivated with $P$. phytofirmans PsJN before infection and $6 \mathrm{~h}$ after infection (Fig. 5). With the JA/ET signaling pathways, the expression levels of four related genes were analyzed, $L I P$ OXYGENASE 2 (LOX2; AT3G45140), VEGETATIVE STORAGE PROTEIN 2 (VSP2; AT5G24770), the transcription factors MYC2 (AT1G32640), and ERF1 (AT3G23240). As expected by the previous result for PDF1.2, the expression level of ERFI was significantly higher in strain PsJN-treated plants 1 and $6 \mathrm{~h}$ after DC3000 infection, whereas LOX2 was up-regulated by strain PsJN and, after the infection event, its expression was downregulated in strain PsJN-treated plants. Additionally, MYC2 was up-regulated $6 \mathrm{~h}$ after infection and down-regulated 24 hpostinfection (hpi) in strain PsJN-treated plants. On the other hand, no significant changes were detected in VSP2 expression between control and strain PsJN-treated plants.

\section{$P$. phytofirmans PsJN induces SA production in $A$. thaliana plants.}

Induction by strain PsJN of genes encoding for the ICS1 enzyme, the SA-marker gene $P R l$, and the SA-inducible gene 
WRKY54 suggested that SA should be produced in response to this PGPR. In order to confirm this hypothesis, the amounts of free SA and glycosylated SA (SAG) were measured in plants cocultivated with $P$. phytofirmans PsJN. As shown in Figure 6, significantly higher levels of free SA and SAG were detected in plants inoculated with strain PsJN, representing $1.57 \mu \mathrm{g}$ SA per gram of FW, in comparison with control plants, which presented $0.35 \mu \mathrm{g}$ SA per gram of FW. The same pattern was observed $24 \mathrm{~h}$ after DC3000 infection, where PsJN-treated plants presented significantly more free SA and SAG than control plants (Fig. 6). After $48 \mathrm{~h}$ of the infection, there were no significant differences in the amount of SA between plants treated or not with P. phytofirmans PsJN (Fig. 6).

\section{P. phytofirmans PsJN does not induce protection in mutant plants impaired in SA and JA/ET signaling pathways.}

To reinforce the findings obtained at the molecular level with the transcriptional analyses, in which the involvement of SA
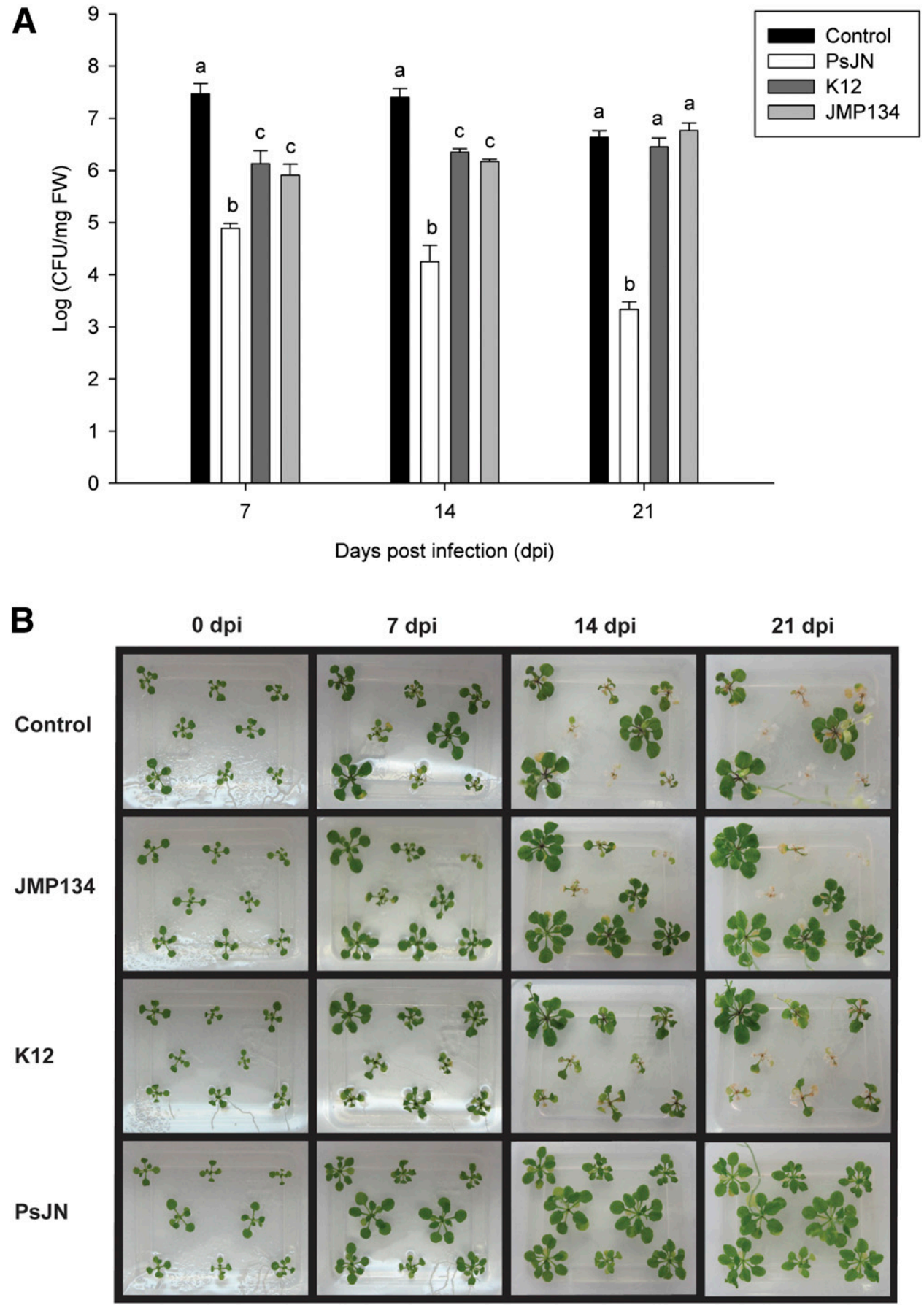

Fig. 3. Response to Pseudomonas syringae pv. tomato DC3000 infection of Arabidopsis thaliana plants cocultivated with plant growth promoting rhizobacteria (PGPR) or non-PGPR strains. A, Proliferation of virulent DC3000 in rosettes of Arabidopsis plants cocultivated with or without Paraburkholderia phytofirmans PsJN and plants cocultivated with the non-PGPR Escherichia coli K12 and Cupriavidus pinatubonensis JMP134. Measurements were done at 7, 14, and 21 days postinfection (dpi). Each bar represents the log-transformed mean of six individual plants (CFU per gram of leaf fresh weight) and its standard error. Different letters on the bars indicate statistically significant differences among treatments (one-way analysis of variance, $P<0.05$; Tukey's test, $P<0.05$ ). Results are representative of two independent experiments. B, Symptomatology of infected A. thaliana plants over three weeks. Representative photographs of A. thaliana rosettes exposed to different bacterial treatments (plants cocultivated with strains PsJN, JMP134, and K12 and noninoculated plants). Results were recorded at $0,7,14$, and 21 days postinfection (dpi). 
and JA/ET signaling pathways seems to be important for the protection conferred by $P$. phytofirmans PsJN, infection assays with several plants mutant in SA, JA, and ET pathways were performed. The results of single mutant plants infected with DC3000 showed that strain PsJN still protects sid2-2 plants (SA induction deficient 2), a mutant deficient in SA biosynthesis (Wildermuth et al. 2001) (Fig. 7A). Similarly, coil-1 (coronatine insensitive 1), a JA-insensitive mutant (Xie et al. 1998), and ein2-1 (ET insensitive 2), an ET-insensitive mutant (Alonso et al. 1999), could resist disease as well as the wild-type plants when they were inoculated with strain PsJN (Fig. 7A). These results suggest that more than one hormone signaling pathway is involved in the induced resistance triggered by $P$. phytofirmans PsJN in Arabidopsis plants. Therefore, an approach using double, triple, and quadruple mutants was applied (Tsuda et al. 2009). The set of double mutants comprised the three possible combinations of SA, JA, and ET pathways. So, dde2-2/ein21 , ein2-1/sid2-2, and dde2-2/sid2-2 double mutants preserve the SA, JA, or ET signaling pathways, respectively. The triple and quadruple mutants, dde2-2/ein2-1/sid2-2, and
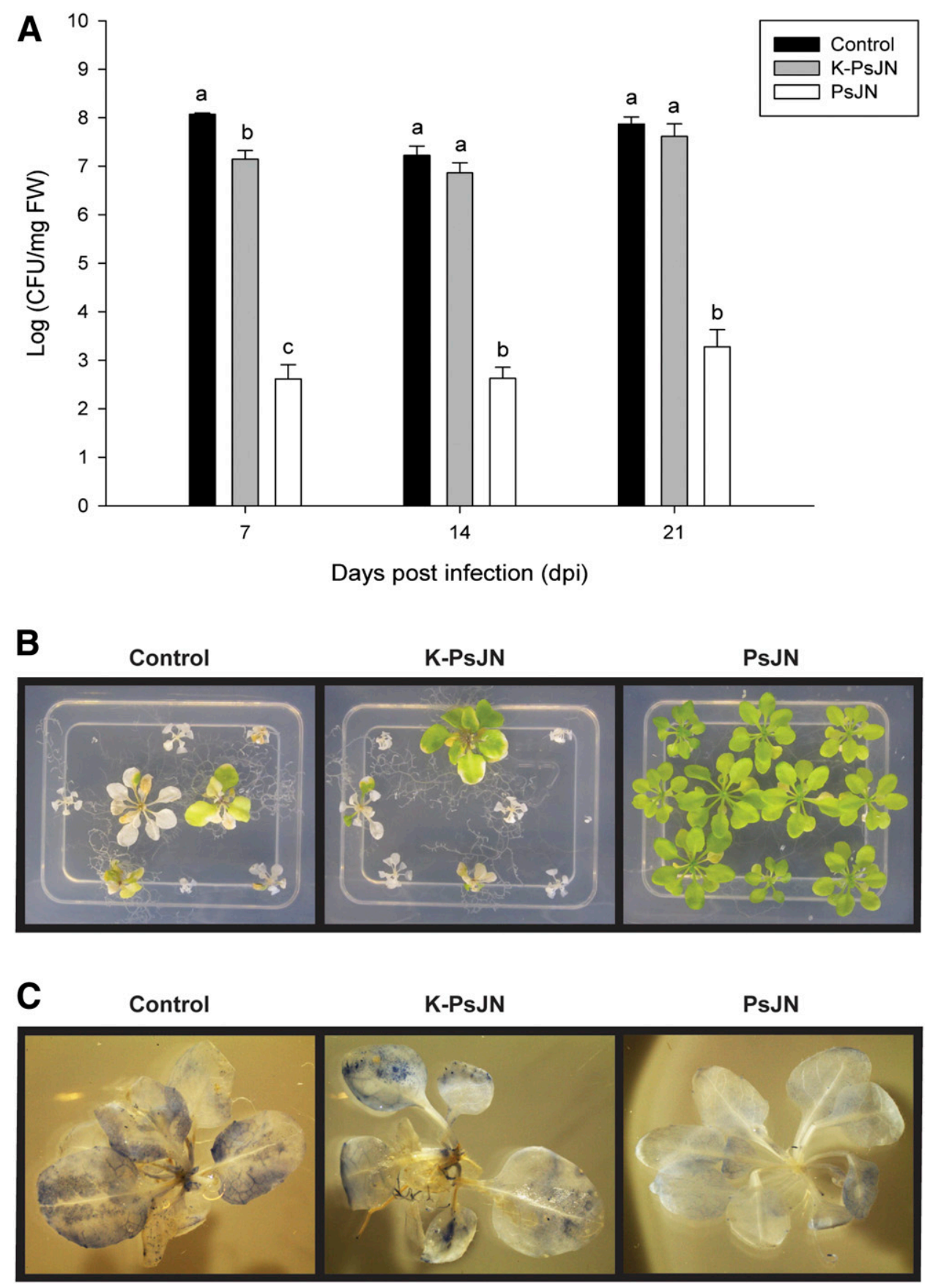

Fig. 4. Response to Pseudomonas syringae DC3000 infection of Arabidopsis thaliana plants cocultivated with metabolically active or inactive Paraburkholderia phytofirmans PsJN. A, Proliferation of virulent DC3000 (disease progression) 21 days after infection in rosettes of Arabidopsis plants cocultivated with or without strain PsJN and mercuric chloride-treated bacteria (K-PsJN). Each bar represents the log-transformed mean of six individual plants (CFU per gram of leaf fresh weight) and its standard error. Different letters on the bars indicate statistically significant differences among treatments (One-way analysis of variance, $P<0.05$; Tukey's test, $P<0.05$ ). Results are representative of two independent experiments. B, Symptomatology of $A$. thaliana plants after 21 days of infection. Representative photographs of $A$. thaliana rosettes exposed to different treatments: plants cocultivated with strain PsJN, K-PsJN, and noninoculated and infected with the virulent DC3000. C, Histochemical detection of superoxide anion in A. thaliana after 21 days of infection. Representative photographs of Arabidopsis plants cocultivated or not with strain PsJN or with K-PsJN, after DC3000 infection. 
dde2-2/ein2-1/pad4-1/sid2-2 are defective in SA, JA, and ET signaling pathways. DDE2 (DELAYED DEHISCENCE 2) is essential for JA biosynthesis (Park et al. 2002), whereas PAD4 (PHYTOALEXIN DEFICIENT 4) is important for SA accumulation in response to some SA-inducing stimuli and has an SA-independent immune function (Glazebrook et al. 2003; Jirage et al. 1999). Three weeks after challenge with DC3000, only mutants impaired in the three hormonal signaling pathways exhibited no significant differences in DC3000 population between control and strain PsJN-treated plants (Fig. 7B). Altogether, these results confirmed that $P$. phytofirmans PsJN protects A. thaliana through the activation of defenses dependent of the SA- and JA/ET signaling pathways.

\section{A nonmotile mutant strain of $P$. phytofirmans PsJN has reduced ability to protect $\boldsymbol{A}$. thaliana plants against virulent Pseudomonas syringae DC3000.}

It has been reported that a synthetic 22-amino acid flagellin peptide derivative from $P$. phytofirmans PsJN is differentially recognized by the flagellin sensing system (FLS2-flg22) of grapevine and Arabidopsis (Trdá et al. 2014). In order to elucidate the role of flagellin bacterial elicitor of the defense response triggered by strain PsJN in Arabidopsis plants, a $P$. phytofirmans strain defective in the fliA gene was generated (PsJN $\triangle$ fliA). This gene encodes an alternative sigma factor $(\sigma 28)$ necessary for the transcription of flagellin and other proteins required in late flagellar biogenesis in different bacteria, including Burkholderia species (Anderson et al. 2010;
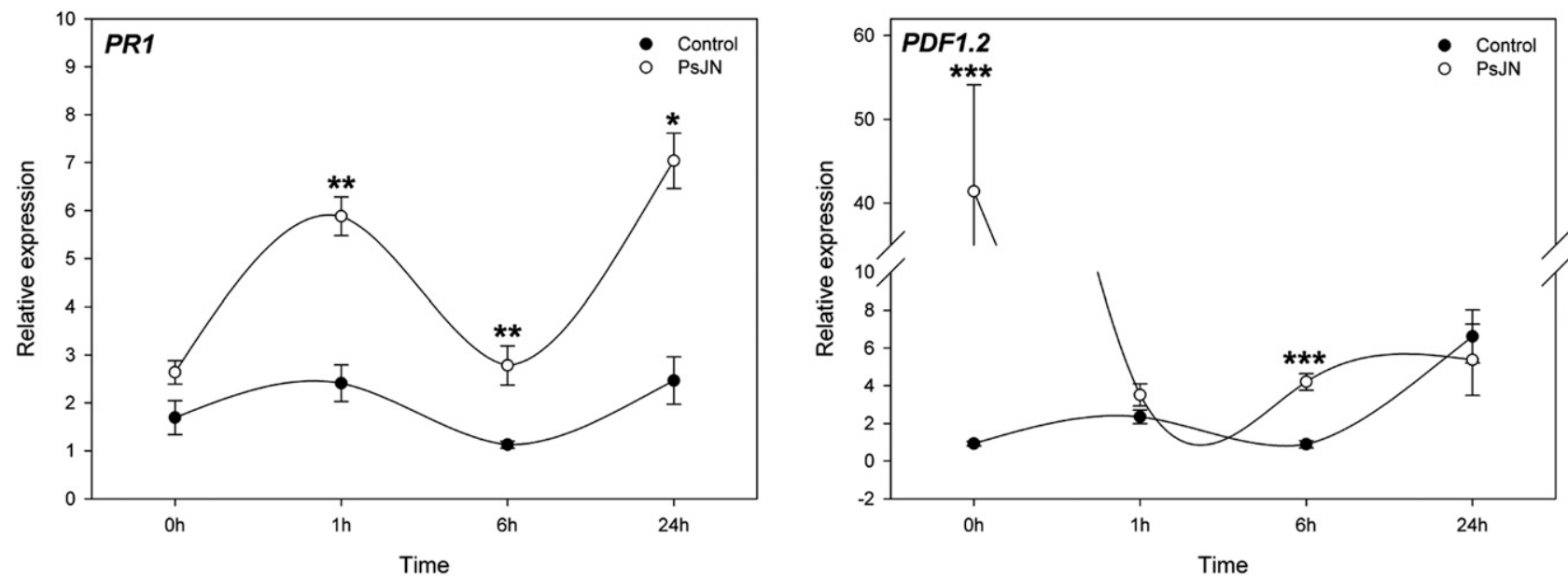

Fig. 5. Expression patterns of Arabidopsis thaliana defense-related genes in response to Paraburkholderia phytofirmans PsJN, alone $(0 \mathrm{~h})$ or in the presence of Pseudomonas syringae DC3000 (1, 6, and 24 h). Quantitative reverse transcription-polymerase chain reaction determinations of relative expression of $P R 1$ (PATHOGENESIS-RELATED GENE 1) and PDF1.2 (PLANT DEFENSIN 1.2) genes in complete plants, 13 days after sowing, cocultivated or not with strain PsJN. Total RNA was extracted before DC3000 infection $(0 \mathrm{~h})$ and 1,6 , and $24 \mathrm{~h}$ after infection. Data are means \pm standard error of three to five biological replicates per treatment, each considering tissue from four plants and two technical replicates. Normalization was performed with the housekeeping SAND family gene (AT2G28390). Asterisks indicate statistically significant differences among treatments in a particular time (one-way analysis of variance, $P<0.05$; Student's $t$ test, one asterisk [*] $P<0.05$; two asterisks [**] $P<0.01$; three asterisks [***] $P<0.001$ ).

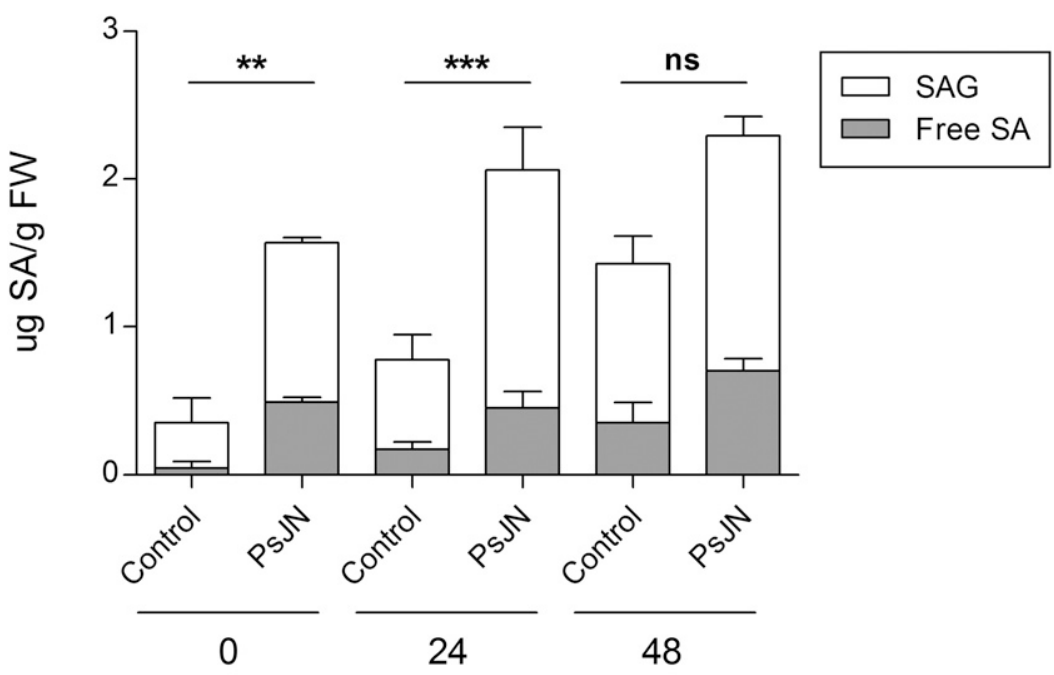

Hours post infection (hpi)

Fig. 6. Salicylic acid (SA) levels in Arabidopsis thaliana plants cocultivated with or without Paraburkholderia phytofirmans PsJN. Free SA (gray bars) and glycosylated SA (SAG) (white bars) levels in complete plants 13 days after sowing (four rosette leaves, LP.04 stage) were quantified in Arabidopsis plants inoculated with or without strain PsJN $(0 \mathrm{~h})$ and also 24 and $48 \mathrm{~h}$ postinfection with DC3000. Data are means \pm standard deviation of three biological replicates, where each biological replicate represents a pool of $0.5 \mathrm{~g}$ of whole plants. Asterisks indicate statistically significant differences among treatments (two-way analysis of variance, $P<0.05$; Tukey's test, two asterisks [**] indicate $P<0.01$; three asterisks [***] $P<0.001$; ns, no significant differences). 
Chilcott and Hughes 2000; Kim et al. 2007). The P. phytofirmans fliA mutant was rendered nonmotile (Fig. 8A), with a similar phenotype to that reported for Burkholderia glumae (Kim et al. 2007). Additionally, the mutant strain PsJN $\Delta$ fliA produced less and more fragile biofilm than the wild-type strain (Fig. 8B), which is consistent with studies in strains of Burkholderia cenocepacia and Burkholderia pseudomallei that found flagellum-mediated motility is important for biofilm formation (Saldías et al. 2008; Tunpiboonsak et al. 2010). Results of the infection assay in plants cocultivated with the mutant strain PsJN $\Delta f l i A$, the wild-type strain PsJN, and noninoculated plants showed that strain PsJN $\Delta$ fliA had reduced ability to protect Arabidopsis plants compared with the wild-type strain, as measured by DC3000 population (Fig. 8C) and disease symptomatology (data not shown). However, the mutant strain still provided a degree of protection compared with noninoculated plants (Fig. 8C).

The levels of endophytic and epiphytic colonization of this mutant strain were similar to the wild-type strain (data not shown).

\section{DISCUSSION}

This report demonstrates, for the first time, that $P$. phytofirmans PsJN protects, throughout the entire life cycle, A. thaliana plants against the common phytopathogen Pseudomonas syringae pv.
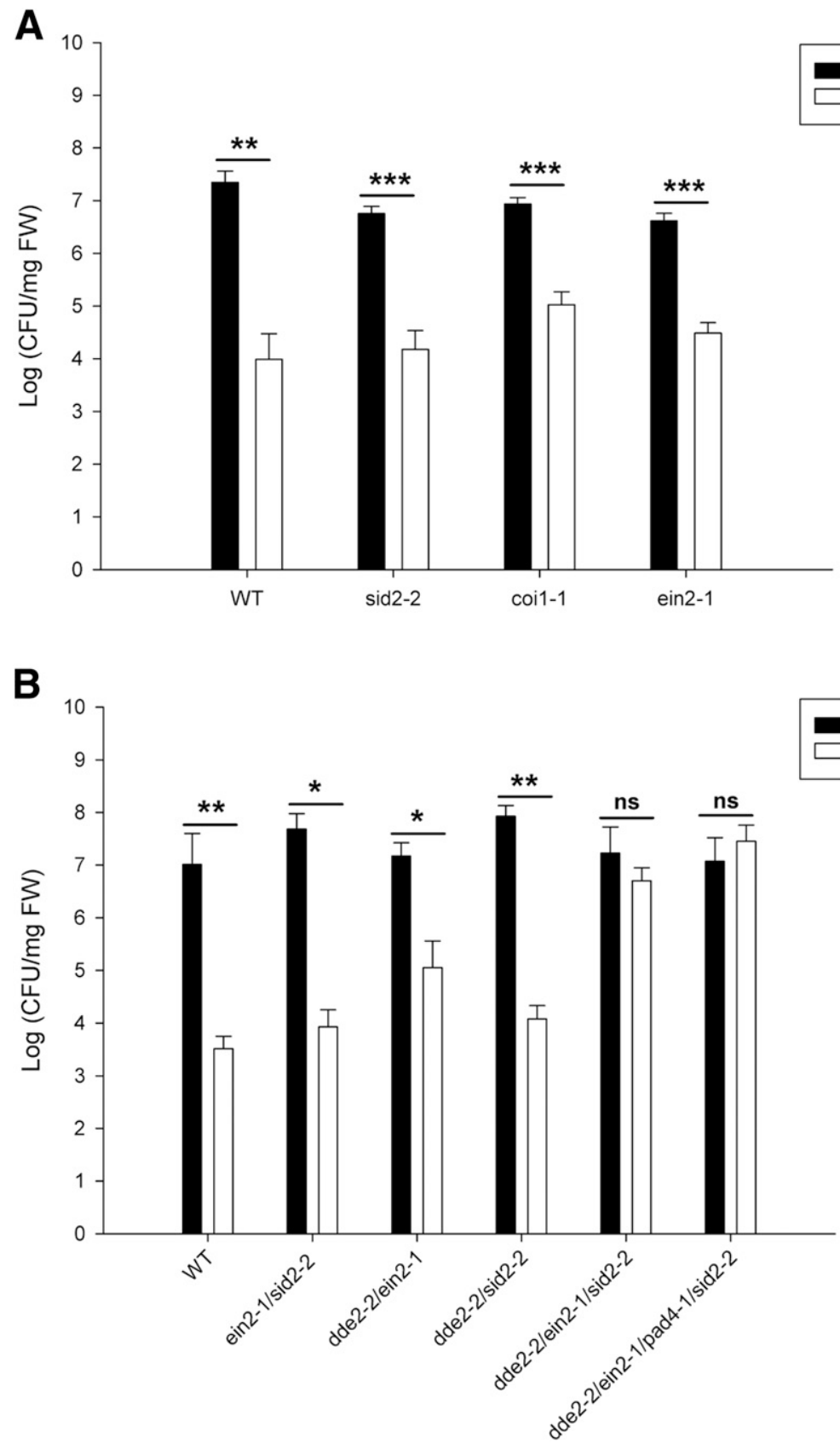

Fig. 7. Response to Pseudomonas syringae DC3000 infection of Arabidopsis hormonal mutant plants cocultivated with or without Paraburkholderia phytofirmans PsJN. Proliferation of virulent DC3000 21 days after infection in rosettes of Arabidopsis wild-type plants and A, single mutant plants (sid2-2, coil-1, ein2-1), or B, double, triple, and quadruple mutant plants (dde2-2/ein2-1, dde2-2/sid2-2, dde2-2/ein2-1/sid2-2, and dde2-2/ein2-1/pad4-1/sid2-2), cocultivated with or without strain PsJN. Each bar represents the log-transformed mean of six individual plants (CFU per gram of leaf fresh weight) and its standard error. Asterisks indicate statistically significant differences among treatments. For data in A, unpaired $t$ test, two asterisks $(* *)$ indicate $P<0.01 ;$ three asterisks $(* * *), P<0.001$. For data in B, Mann-Whitney test, one asterisk $(*)$ indicates $P<0.05$; two asterisks $(* *), P<0.01$; ns, no significant differences. Results are representative of two independent experiments. 
tomato DC3000. This phenomenon is not explained by production of antimicrobials by strain PsJN thus affecting growth of this phytopathogen (data not shown). This protection is due to the activation of induced resistance in the plant, which strongly activates the expression of key defense-related genes belonging to the SA-, JA- and ET-signaling pathways. Protection conferred by P. phytofirmans PsJN to Arabidopsis plants to the pathogenic bacterium Pseudomonas syringae requires metabolically active cells, as plants cocultivated with heat-killed bacteria (HK-PsJN) or inactivated bacteria with conserved cell integrity (K-PsJN) exhibit disease symptoms caused by Pseudomonas syringae pv. tomato infection and higher population levels of the pathogenic bacterium in comparison with strain PsJN-treated plants. Metabolically active PsJN cells are also required to confer salt tolerance to A. thaliana (Ledger et al. 2016; Pinedo et al. 2015). The specificity of Arabidopsis protection to Pseudomonas syringae DC3000 infection by $P$. phytofirmans PsJN is supported by the inability of two other bacterial strains (E. coli $\mathrm{K} 12$ and $C$. pinatubonensis JMP134) to prevent disease symptoms and to control phytopathogen population levels, indicating that plant protection over time is not provoked by shared MAMPs. MAMPs or 'general elicitors,' such as flagellin, lipopolysaccharides, and elongation factor Tu from gram-negative bacteria (Mishina and Zeier 2007), are recognized by the plant innate immune system through the action of

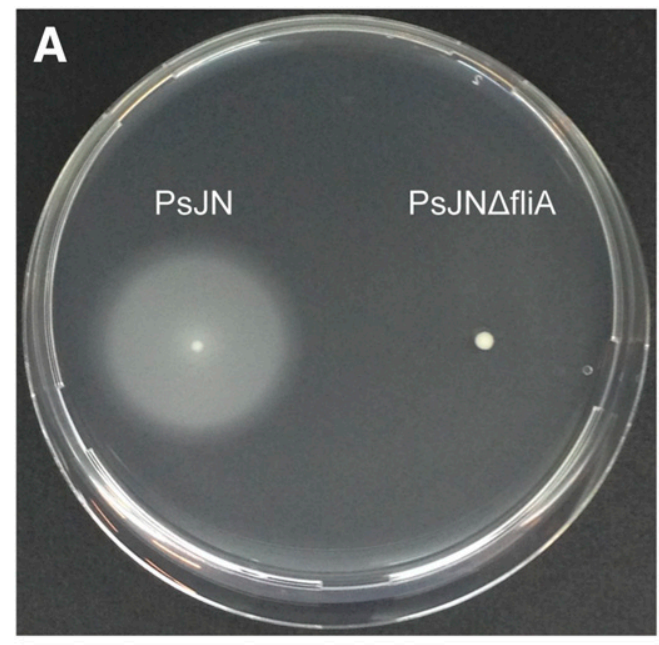

$\mathbf{B}$

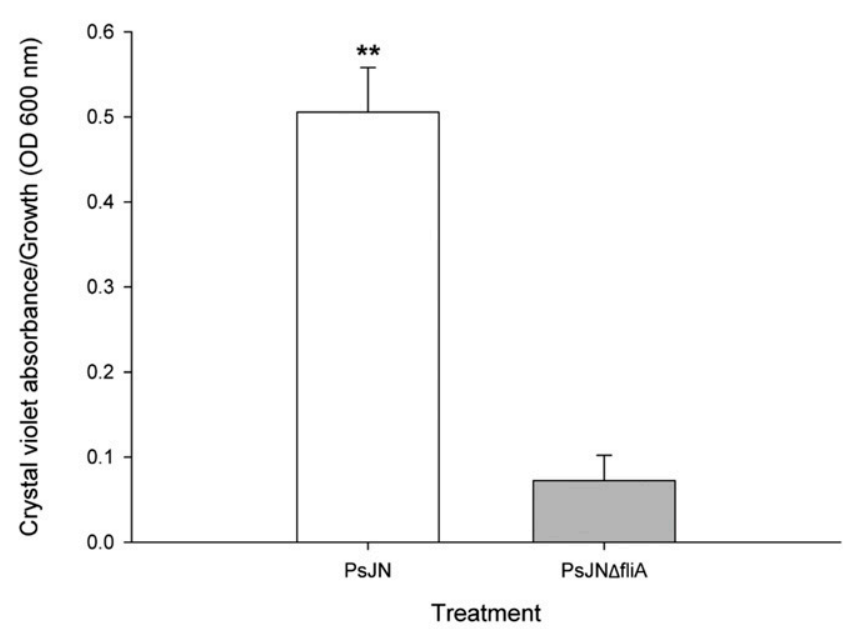

C

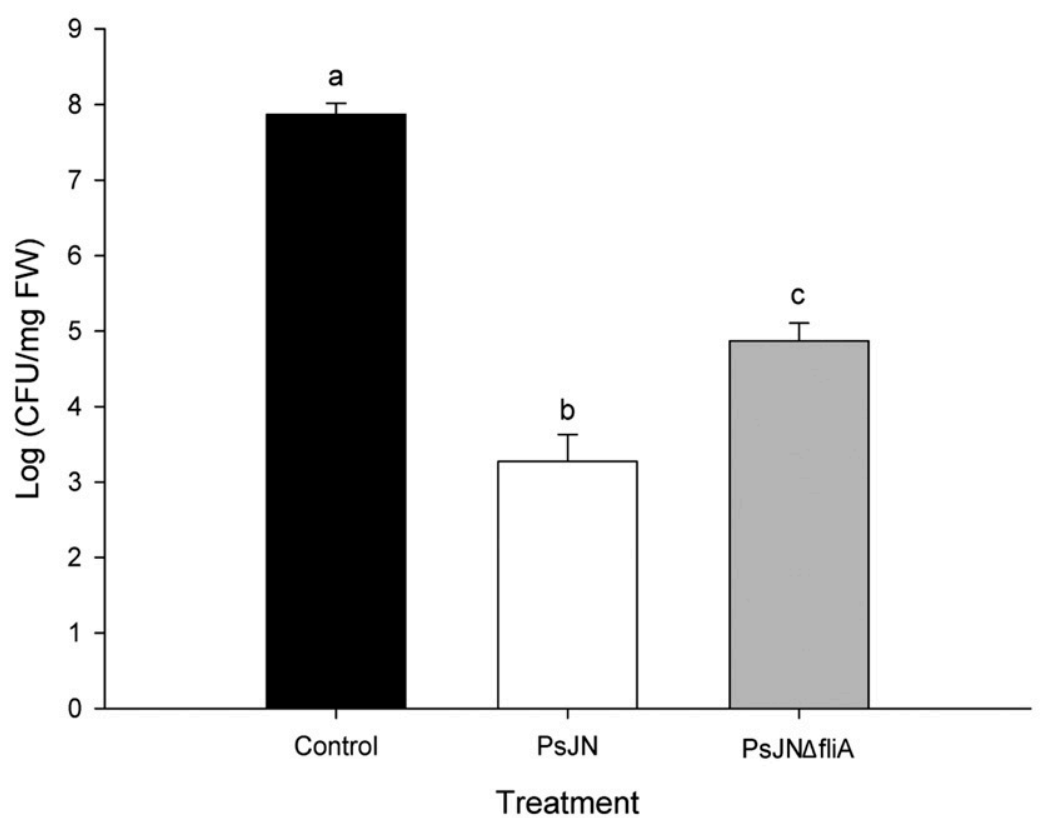

Fig. 8. Motility, biofilm production, and Pseudomonas syringae DC3000 biocontrol in Arabidopsis thaliana plants cocultivated with the Paraburkholderia phytofirmans mutant strain PsJN $\Delta$ fliA. A, Representative photograph of swimming motility assay 5 days after placing the initial inocula onto the plate. Swimming motility was tested using a minimal medium containing $10 \mathrm{mM}$ fructose and $0.25 \%$ agar. P. phytofirmans PsJN (wild type) was able to swim (growth zone present around initial inoculum). In contrast, the mutant strain PsJN $\Delta$ fliA did not show a growth zone around its initial inoculum. The assay was done in triplicate. B, Biofilm production assay of strain PsJN and its fliA mutant derivative growing $72 \mathrm{~h}$ in microplates containing $50 \mathrm{mM}$ mannitol. Biofilms were exposed to $0.1 \%$ (wt/vol) of crystal violet dye after washing with abundant water. Dry biofilms were exposed to absolute ethanol and, after 30 min solutions were measured through absorbance at $600 \mathrm{~nm}$ by spectrophotometry. Biofilm formation was normalized by the growth of the respective strain. Each bar represents the mean of five independent experiments and its standard error. Asterisks indicate statistically significant differences among treatments (Mann Whitney test, $P<0.01)$. C, Pseudomonas syringae DC3000 population levels in Arabidopsis plants alone or cocultivated with wild-type strain $P$. phytofirmans or its fliA mutant derivative. Measurements were taken 21 days after infection. Each bar represents the log-transformed mean of six individual plants (CFU per gram of leaf fresh weight) and its standard error. Different letters on the bars indicate statistically significant differences among treatments (one-way analysis of variance, $P<0.05$; Tukey's test, $P<0.05$ ). 
pattern recognition receptors located at the plasma membrane and result in MTI (Pieterse et al. 2009; Thilmony et al. 2006; Trdá et al. 2014). Successful recognition of these MAMPs results in a mild but effective activation of the plant immune responses in systemic tissues, $\mathrm{H}_{2} \mathrm{O}_{2}$ production, pathogenesis-related (PR) gene induction, and callose deposition (Mishina and Zeier 2007; Van Wees et al. 2008). However, virulent pathogens have acquired effectors that suppress MTI and the disease unavoidably proceeds, resulting in effector-triggered susceptibility (Pieterse et al. 2009; Thilmony et al. 2006). Results reported here are in concordance with this observation, as plants cocultivated with $E$. coli or C. pinatubonensis only contained the disease (Pseudomonas syringae pv. tomato proliferation) at the beginning of infection (14 dpi) (Fig. 3), suggesting that MTI was triggered, leading to the activation of the $P R 1$ gene (Supplementary Fig. S2). Accordingly, $P$. phytofirmans PsJN must elicit a stronger defense mechanism than MTI (i.e., induced resistance) in Arabidopsis plants to limit the disease development over the time.

The activation of defense-related genes can be due to one or more of the SA, JA, or ET signaling pathways, which, in turn, are highly interconnected (Memelink 2009; Pieterse et al. 2009; 2012; Van der Does et al. 2013). Nevertheless, the particular hormone-signaling pathway activated by the colonization of an ISR-inducing PGPR in order to cope with a pathogen attack is specific to the plant species, the pathogenic bacterium, and the PGPR strain combination (De Vleesschauwer and Höfte 2009). For instance, the ISR-inducing PGPR $P$. aeruginosa 7NSK2 triggers ISR in Arabidopsis plants in a SA-independent manner (Ran et al. 2005), but the same PGPR in tobacco plants triggers ISR through the SA signaling pathway (De Meyer et al. 1999). On the other hand, Bacillus subtilis FB17 activates ISR in Arabidopsis through the SA and ET pathway (Rudrappa et al. 2010). Remarkably, B. cereus AR156 can trigger ISR via simultaneous activation of the SA- and JA/ET-signaling pathways, resulting in an enhanced level of induced protection in Arabidopsis due to the activation of $P R 1, P R 2, P R 5$, and PDF1.2 defense genes (Niu et al. 2011). Thus, several genes representative of SA and JA/ET pathways were selected to study induction of resistance in Arabidopsis by strain PsJN. In the case of the ICS1 gene, which encodes the enzyme isochorismate synthase, which is required to synthesize SA in plants (Strawn et al. 2007; Wildermuth et al. 2001), its expression level was higher in strain PsJN-treated plants compared with control plants prior to DC3000 infection. This is in agreement with the fact that strain PsJN stimulated the production of SA in Arabidopsis plants before and $24 \mathrm{~h}$ after the challenge with the pathogenic bacterium (Fig. 6). Accordingly, it has been previously reported that, in cell cultures of Vitis vinifera, free SA (265 ng per gram of FW) was detected in response to $P$. phytofirmans PsJN inoculation (Bordiec et al. 2011). As expected, the expression level of the $P R l$ gene was significantly higher in plants cocultivated with $P$. phytofirmans PsJN in all measured times after Pseudomonas syringae pv. tomato infection $(1,6$, and $24 \mathrm{~h}$ ) (Fig. 5). PRl is a late SAresponsive gene that has its peak of expression $24 \mathrm{~h}$ after SA treatment or after an incompatible interaction with an avirulent phytopathogen (Asai et al. 2014; Blanco et al. 2009; Uquillas et al. 2004). However, PRl expression in Arabidopsis is even later (72 and $120 \mathrm{hpi}$ ) with a virulent phytopathogen challenge (Asai et al. 2014). Notably, Arabidopsis plants treated with strain PsJN and infected with virulent DC3000 showed increased expression of the defense gene $P R l$ significantly earlier. Additionally, expression of a large set of $W R K Y$ genes is induced by SA, including WRKY54 and WRKY70, the latter of which can regulate the expression of SA-responsive genes, such as PRI (Van der Does et al. 2013). In a previous transcriptomic study by our group (Poupin et al. 2013), P. phytofirmans PsJN was shown to upregulate the expression of WRKY70 in Arabidopsis plants. Notably, results reported in the present study indicated that, in plants cocultivated with strain PsJN, the expression of WRKY54 was down-regulated before Pseudomonas syringae pv. tomato infection; however, after the infection event, its expression was up-regulated in the same plants. Remarkably, single sid2-2 mutant plants (deficient in SA biosynthesis) infected with DC3000 still were protected by $P$. phytofirmans (Fig. 7A). In addition, strain PsJN deficient in flagella (PsJN $\Delta f l i A$ ) that did not show increased PRI gene expression provided a degree of protection against this pathogen attack (Fig. 8C), suggesting that the SA signaling pathway is only partially involved in the protection of Arabidopsis by $P$. phytofirmans PsJN.

Because a fine-tuning crosstalk between the defense hormones SA and JA plays a central role in the modulation of the plant immune signaling network (Mur et al. 2006), a selected group of key genes belonging to the JA/ET signaling pathway was analyzed. In Arabidopsis, the JA-responsive genes PDF 1.2 and VSP2 are highly sensitive to suppression by SA in an NPR1-dependent manner, when ET signaling is not stimulated (León-Reyes et al. 2009; Pieterse et al. 2012). Otherwise, when ET signaling is stimulated, the NPR1 dependency of SA-JA crosstalk is bypassed (León-Reyes et al. 2009). The final outcome of the SA-JA signal dynamic during the complex interactions between plants and their attackers can be shaped by the ET present in the signal signature produced upon attack (Pieterse et al. 2012). For instance, in Arabidopsis, ET potentiates SA-responsive PRI expression (De Vos et al. 2007; Niu et al. 2011; Pieterse et al. 2012). Results reported here indicate that LOX2, an enzyme involved in JA biosynthesis induced by wounds or mechanical damage (Chauvin et al. 2013), was upregulated in strain PsJN-treated plants before DC3000 infection, which is in agreement with that reported previously by Poupin et al. (2013). However, after the infection event, LOX2 expression was down-regulated in plants cocultivated with strain PsJN over all measured times. This result is in accordance with previous reports that demonstrate that endogenously accumulated SA has an inhibitory effect on LOX2 gene expression and JA formation (Spoel et al. 2003). Additionally, PDF1.2 gene is synergistically induced by a combination of JA and ET (Memelink 2009). As expected, the expression level of PDF1.2 was significantly higher due to the inoculation of strain PsJN, which is according to previous reports (Poupin et al. 2013) and was also up-regulated $6 \mathrm{~h}$ after DC3000 infection in strain PsJN-treated plants (Fig. 5).

Many reports describe an antagonistic interaction between SA and JA pathways, but synergistic interactions have been reported as well (Liu et al. 2016; Mur et al. 2006). The relative concentrations of SA and JA in plants are important in determining gene expression levels. For instance, a transient synergistic enhancement in the expression of genes associated with both JA (PDF1.2) or SA (PRI) signaling pathways when both hormones SA and JA are applied at low concentrations was observed in tobacco plants (Mur et al. 2006). Even more, a recent report has shown that an early induction of JAresponsive genes and de novo JA synthesis following SA accumulation is activated through the SA receptors NPR3 and NPR4 instead of the JA receptor COI1 (Liu et al. 2016). It is quite possible that a synergistic interaction between SA and JA would be taking place in Arabidopsis plants inoculated with $P$. phytofirmans PsJN, because ICS1 and LOX2 were activated in plants cocultivated with strain PsJN, and, after Pseudomonas syringae pv. tomato infection, $P R 1$ and $P D F 1.2$ were highly induced in the same plants.

Since P. phytofirmans PsJN induced the expression of ICS1, $P D F 1.2$, and $L O X 2$ genes (Fig. 5) and stimulated the production 
of SA (Fig. 6), A. thaliana plants inoculated with this PGPR strain were better prepared, at least at the molecular and metabolic level, to face the disease caused by the virulent strain of Pseudomonas syringae DC3000. Furthermore, early expression of the defense gene $P R l, 1$ hpi instead of its normal timing (72 hpi) (Asai et al. 2014), suggests that Arabidopsis plants cocultivated with strain PsJN were in a priming state before infection. Therefore, these plants could respond faster and stronger upon pathogen attack, resulting in enhanced resistance. Additionally, the activation of WRKY54, MYC2, and ERF1 defense genes in strain PsJN-treated plants after Pseudomonas syringae pv. tomato challenge likely contributed to reduced disease severity and to prevent pathogen proliferation in the leaves.

Moreover, the participation of the SA, JA, and ET hormones in the induced resistance triggered by $P$. phytofirmans PsJN in Arabidopsis plants was confirmed with several mutant lines impaired in these hormonal signaling pathways, in which, only in the triple and quadruple mutants dde2-2/ein2-1/sid2-2 and dde2-2/ein2-1/pad4-1/sid2-2, strain PsJN could not protect plants against the pathogenic bacterium (Fig. 7). Concerning results using double mutant lines, strain PsJN can protect its host if at least one hormonal signaling pathway remains intact (Fig. 7B). Therefore, it is quite clear that the PGPR $P$. phytofirmans PsJN induced resistance in A. thaliana by activating, either, SA-, JA- or ET-dependent signaling pathways. Mediation of induced resistance by these three signaling pathways has also been reported for the PGPR B. cereus AR156 in A. thaliana (Niu et al. 2011); however, PGPR-mediated induced resistance by the three most important hormonal pathways for plant defense has not been widely reported so far. It is very interesting that $P$. phytofirmans PsJN can activate the SA and JA/ET signaling pathways on plants that it colonizes, because plants will be better prepared to face an attack by either biotrophic or necrotrophic pathogens. In fact, a recently published study (Miotto-Vilanova et al. 2016) showed that strain PsJN protects grapevine plants from a necrotrophic pathogen (B. cinerea) by the activation of $P R I$ and JA-related genes and, also, by an accumulation of starch and callose deposition in leaves.

After demonstrating that strain PsJN is able to trigger induced resistance in Arabidopsis plants, we sought to determine which effector molecules from strain PsJN elicit the defense response in the plant. To tackle this challenge, infection assays with killed but cellularly intact strain PsJN (K-PsJN, MAMPs remained intact) were carried out. Seven days after the infection, K-PsJN-treated plants presented fewer CFU of the pathogen than control plants (Fig. 4A); however, this difference disappeared on 14 and $21 \mathrm{dpi}$. These results can be explained by the activation of MTI; nevertheless, this innate immune response is not sufficient to contain the proliferation of the virulent strain DC3000 in K-PsJN-treated plants, because this pathogenic bacterium represses three genes associated with basal defense response in Arabidopsis, FLS2, FRK1, and WRKY22 (Thilmony et al. 2006). This is reflected in the DC3000 population at 14 and 21 days after infection, when plants treated with K-PsJN do not have significant differences with respect to noninoculated plants (Fig. 4A). Therefore, strain PsJN MAMPs such as flagella or lipopolysaccharides, removed from their functional context and considered solely for their molecular composition, are not sufficient to fully induce resistance in plants. Additionally, the mutant lacking flagella (PsJN $\Delta f l i A)$ still displays a significantly high level of control of the pathogen population size in comparison with noninoculated plants (Fig. 8), reinforcing the idea that the flagellum (or the ability to move) could be only one component of a set of elicitors (or functions) able to induce resistance in Arabidopsis.
The notion that metabolically active $P$. phytofirmans PsJN triggers induced resistance in Arabidopsis plants is also supported by a study done with a synthetic flg22 peptide derived from $P$. phytofirmans PsJN in A. thaliana and $V$. vinifera (Trdá et al. 2014). The authors demonstrated that the flagellin receptor of V. vinifera (VvFLS2) differentially recognizes flg22 from strain PsJN from pathogenic bacteria, suggesting that flagellin from the beneficial PGPR $P$. phytofirmans has evolved to evade the grapevine immune recognition system. Accordingly, there is no growth inhibition, nor inhibition of $\mathrm{H}_{2} \mathrm{O}_{2}$ production, in grapevine plants. The opposite effects were observed in Arabidopsis plants, in which flg22 of $P$. phytofirmans induced $\mathrm{H}_{2} \mathrm{O}_{2}$ production and growth inhibition in a similar fashion to effects triggered by the pathogen-derived flg22 peptides from Pseudomonas aeruginosa or Xanthomonas campestris (Trdá et al. 2014). This antecedent reinforces the idea that $P$. phytofirmans PsJN needs to be metabolically active to modulate plant regulatory mechanisms, including defense mechanisms. This is aligned with the fact that colonization of roots by ISR-eliciting PGPR requires local suppression of MAMP-triggered immunity to protect the PGPR against MAMP-triggered production of antimicrobial compounds such as phytoalexins (Millet et al. 2010; Pieterse et al. 2014). Downregulation of root immune responses has been previously described for the PGPF genus Trichoderma and for ISR-inducing PGPR such as B. subtilis FB17 and Pseudomonas fluorescens WCS417 (Pieterse et al. 2014). Specifically, Pseudomonas fluorescens WCS417 suppresses the activation of defense genes in Arabidopsis roots that are triggered by flg22 (Millet et al. 2010). Based in the results shown by Poupin et al. (2013) and Trdá et al. (2014), it can be suggested that $P$. phytofirmans PsJN exerts a similar suppression as Pseudomonas fluorescens WCS417 in Arabidopsis roots.

To the best of our knowledge, the present study is the first report showing that the PGPR $P$. phytofirmans PsJN protects A. thaliana against a virulent pathogenic bacterium (Pseudomonas syringae DC3000) and, also, established that the underlying mechanism of the plant protection is the activation of induced resistance. Moreover, strain PsJN can trigger induced resistance in Arabidopsis plants either by the SA-, JA-, or ETsignaling pathways; therefore, plants should be better prepared to face an attack either by biotrophic or by necrotrophic pathogens.

\section{MATERIALS AND METHODS}

\section{Plant growth conditions and} bacterial inoculation treatments.

$P$. phytofirmans PsJN was routinely grown in minimal saline medium (Dorn et al. 1974), containing $10 \mathrm{mM}$ fructose, in an orbital shaker $(120 \mathrm{rpm})$ at $30^{\circ} \mathrm{C}$. Cell suspensions were subsequently collected and adjusted to $1 \times 10^{8} \mathrm{CFU}$ per milliliter, as determined by plate counting. A. thaliana wild-type plants were Col-0 ecotype, as were as the background of all mutant lines used in this study. Arabidopsis sid2-2 (Wildermuth et al. 2001) and coil-1 mutants (Xie et al. 1998) were previously described. Seeds of ein2-1 (CS3071) (Alonso et al. 1999), dde2-2/ein2-1 (CS65997), dde2-2/sid2-2 (CS65999), dde22/ein2-1/sid2-2 (CS66004), and dde2-2/ein2-1/pad4-1/sid2-2 (CS66007) (Tsuda et al. 2009) were obtained from the Arabidopsis Biological Resource Center. Seeds were surfacesterilized with $50 \%$ sodium hypochlorite $(100 \%$ commercial laundry bleach) containing $0.1 \%$ Tween 20 , were rinsed four times with sterile water, and were kept at $4^{\circ} \mathrm{C}$ for 4 days, to promote uniform germination. To prepare the inoculated pots (Phytatray 1552; Sigma-Aldrich, St. Louis) for gnotobiotic assays, the initial inoculum of strain PsJN $\left(1 \times 10^{8} \mathrm{CFU} / \mathrm{ml}\right)$ was homogenously diluted in half strength Murashige and 
Skoog medium (50\% MS) 0.8\% agar (Murashige and Skoog 1962) just before gelling, to reach a final inoculum of $1 \times$ $10^{4} \mathrm{CFU} / \mathrm{ml}$ of medium. This inoculum size was previously reported by Poupin et al. (2013) as the optimum to provoke positive effects in A. thaliana plants. Then, sterilized and synchronized seeds were sown, eight per pot, in pots with $50 \%$ MS medium inoculated with or without the strain. Pots were placed in a growth chamber at $22^{\circ} \mathrm{C}$ with a photoperiod of $16 \mathrm{~h}$ light and $8 \mathrm{~h}$ dark.

To assess the effect of heat inactivated bacteria (HK-PsJN, mortality corroborated by plate counting), bacterial cells were heated at $95^{\circ} \mathrm{C}$ for $20 \mathrm{~min}$ and were then used as inoculum at a dilution of $1 \times 10^{4} \mathrm{CFU} / \mathrm{ml}$, as described above. Additionally, to evaluate the effect of metabolically inactive but structurally intact (cell membrane and their MAMPs) cells of strain PsJN, an inoculum of strain PsJN was treated with mercuric chloride $\left(\mathrm{HgCl}_{2}\right)$. The procedure was as follows: $45 \mathrm{ml}$ of an overnight strain PsJN culture was centrifuged three times at $10,000 \times g$ for $5 \mathrm{~min}$ at room temperature to wash the minimal medium culture salts. The pellet was then resuspended in $20 \mathrm{ml}$ of $50 \mathrm{mM}$ phosphate buffer, and the cells were exposed to $20 \mathrm{mM} \mathrm{HgCl}_{2}$ for $1 \mathrm{~min}$. In order to completely remove the $\mathrm{HgCl}_{2}$ and thus prevent damage in plants, the culture was centrifuged three times at $8,000 \mathrm{rpm}$ for $5 \mathrm{~min}$ at room temperature and was resuspended every time in $40 \mathrm{ml}$ of $50 \mathrm{mM}$ phosphate buffer. The final resuspension was carried out with $10 \mathrm{ml}$ of $50 \mathrm{mM}$ phosphate buffer, to adjust cell concentration to an optical density at $600 \mathrm{~nm}\left(\mathrm{OD}_{600}\right)$ of 0.6 (same concentration as the living cells culture). Plate counting corroborated mortality, and cell integrity was verified by optical microscope visualization after staining with safranin dye.

To assess the specificity of strain PsJN in triggering induced resistance in A. thaliana, two additional treatments were performed. One group of plants was sown, in pots containing 50\% MS, $0.8 \%$ agar, and Escherichia coli $\mathrm{K} 12$ at $1 \times 10^{4} \mathrm{CFU} / \mathrm{ml}$, as a bacterium not associated with plants, and another group was sown in the same conditions but with $C$. pinatubonensis JMP134 at $1 \times 10^{4} \mathrm{CFU} / \mathrm{ml}$, as an environmental bacterium neutral for plants (Ledger et al. 2012).

\section{Infection of plants and proliferation assays.}

A virulent strain of the plant pathogen Pseudomonas syringae pv. tomato DC3000 was grown on King's B medium in an orbital shaker $(120 \mathrm{rpm})$ at $28^{\circ} \mathrm{C}$, supplemented with rifampicinn $(50 \mu \mathrm{g} / \mathrm{ml})$ and kanamycin $(50 \mu \mathrm{g} / \mathrm{ml})$ as selection antibiotics. Three-week-old plants (21 DAS) from each treatment were infected on rosettes by spraying $100 \mu \mathrm{l}$ per pot with an inoculum of DC3000 $\left(5 \times 10^{4} \mathrm{CFU} / \mathrm{ml}\right)$ in $10 \mathrm{mM} \mathrm{MgCl}$ or only $10 \mathrm{mM} \mathrm{MgCl}_{2}$, for mock treatments, based on a previously described procedure (Innerebner et al. 2011). Mock treatments never showed any effects on plants. Pots were returned to the growth chamber at $22^{\circ} \mathrm{C}$ with the same photoperiod as above.

In order to measure disease progression, above-ground plant parts (rosettes) from eight independent plants per treatment were taken at $0,7,14,21$, and $28 \mathrm{dpi}$. The $\mathrm{FW}$ of each plant was recorded. Subsequently, to determine DC3000 cell numbers contained in the infected plant tissues, collected rosettes were placed individually into $2-\mathrm{ml}$ tubes containing $1.3 \mathrm{ml}$ of $100 \mathrm{mM}$ phosphate buffer ( $\mathrm{pH} 7$ ) supplemented with $0.2 \%$ ( $\mathrm{vol} / \mathrm{vol})$ of the surfactant silwet L-77 (Lehle Seeds, Round Rock, TX, U.S. A.) (Innerebner et al. 2011). Samples were placed into an orbital shaker $(120 \mathrm{rpm})$ at $28^{\circ} \mathrm{C}$ for $1.5 \mathrm{~h}$. After washing, tenfold serial dilutions were plated onto King's B agar plates supplemented with rifampicin $(50 \mu \mathrm{g} / \mathrm{ml})$ and kanamycin $(50 \mu \mathrm{g} / \mathrm{ml})$. Plates were incubated at $28^{\circ} \mathrm{C}$ for $48 \mathrm{~h}$ and the number of antibiotic-resistant CFU was determined. CFU were normalized by the FW of plants (CFU per milligram of FW) and the values were $\log 10$ transformed. Plants severely damaged by disease could not be handled to obtain enough biomass material for accurate FW determinations. Statistical analyses were done with R software version 3.2.1 (R Development Core Team 2011). One-way analysis of variance (ANOVA) and a Tukey's test were carried out for each timepoint independently.

\section{Symptomatology and plant disease severity index.}

Disease symptoms of infected A. thaliana plants were recorded by photographing rosette areas every week since the day of infection with DC3000 until 28 dpi. The disease severity index was measured based on the number of leaves per plant showing disease symptoms (necrotic or water-soaked spots surrounded by chlorosis), where $0 \%$ means that no leaf presents symptoms and $100 \%$ means that all leaves present symptoms (protocol adapted from Hossain et al. [2007]). At least eight individual plants per treatment were used for this measurement.

\section{Histochemical detection of $\mathrm{O}_{2}^{-}$.}

At 21 dpi, Arabidopsis plants were incubated in phosphatebuffered saline solution ( $137 \mathrm{mM} \mathrm{NaCl}, 2.7 \mathrm{mM} \mathrm{KCl}, 10 \mathrm{mM}$ $\left.\mathrm{Na}_{2} \mathrm{HPO}_{4}, 2 \mathrm{mM} \mathrm{KH} \mathrm{PO}_{4}\right)$ containing $0.06 \mathrm{mM}$ nitroblue tetrazolium, to detect the superoxide radical $\left(\mathrm{O}_{2}^{-}\right)$, after which the plant individuals were cleared in $80 \%$ ethanol at $60^{\circ} \mathrm{C}$ to remove chlorophyll (protocol adapted from Carvalho et al. [2008]). Images were taken with a digital camera coupled to a stereo microscope (Leica S6D, Wetzlar, Germany).

RNA extraction, cDNA synthesis, and qRT-PCR analysis.

Sterilized and synchronized $A$. thaliana seeds were sown in square petri dishes with $50 \%$ MS medium $0.8 \%$ agar, inoculated or not with $P$. phytofirmans PsJN. Plates were placed vertically in a growth chamber at $22^{\circ} \mathrm{C}$ with a photoperiod of $16 \mathrm{~h}$ light and $8 \mathrm{~h}$ dark. At 13 DAS, Arabidopsis plants with four visible leaves (LP.04 stage [Boyes et al. 2001]) were challenged with DC3000 or left as controls (mock treatment) under the same procedure described above. Immediately after infection, four randomly selected mock-treated plants were sampled and stored in 1.5-ml Eppendorf tubes containing RNAlater (Ambion, Austin, TX, U.S.A.), according to the manufacturer's instructions. Five pools with four plants each were collected per treatment (noninoculated plants, mock and strain PsJN-inoculated plants, mock). In the qRT-PCR results, these treatments correspond to $0 \mathrm{~h}$. At 1, 6, and $24 \mathrm{~h}$ after DC3000 infection, four randomly selected Pseudomonas syringae pv. tomato-infected plants were sampled and stored in $1.5-\mathrm{ml}$ Eppendorf tubes containing RNAlater (Ambion), according to the manufacturer's instructions. Five pools with four plants each were collected per treatment (noninoculated plants, Pseudomonas syringae pv. tomato and strain PsJN-inoculated plants, Pseudomonas syringae pv. tomato). In the qRT-PCR results, these treatments correspond to 1, 6, and $24 \mathrm{~h}$. For RNA extraction, plants were ground with a pestle in the Eppendorf tube without the RNAlater solution. Then, total RNA of each sample was extracted, using the Trizol reagent (Invitrogen, Carlsbad, CA, U.S.A.) according to the manufacturer's recommendations.

For cDNA synthesis, $1 \mu \mathrm{g}$ of total RNA treated with DNAse I (RQ1, Promega, Madison, WI, U.S.A.) was reverse transcribed with random hexamer primers, using the Improm II reverse transcription (Promega), following the manufacturer's instructions. Real time RT-PCR was performed using the Brilliant SYBR green QPCR master reagent kit (Agilent Technologies, Santa Clara, CA, U.S.A.) and the Eco real-time PCR detection system (Illumina, San Diego, CA, U.S.A.), as described by Poupin et al. (2013). The PCR mixture $(15 \mu \mathrm{l})$ contained $2.0 \mu \mathrm{l}$ of template cDNA (diluted 1:10) and $140 \mathrm{nM}$ of each primer. Amplification was performed under the following conditions: 
$95^{\circ} \mathrm{C}$ for $10 \mathrm{~min}$, followed by 40 cycles of $94^{\circ} \mathrm{C}, 30 \mathrm{~s} ; 58$ to $62^{\circ} \mathrm{C}, 30 \mathrm{~s}$; and $72^{\circ} \mathrm{C}, 30 \mathrm{~s}$, followed by a melting cycle from 55 to $95^{\circ} \mathrm{C}$. Relative gene expression calculations were conducted as described in the software manufacturer's instructions; an accurate ratio between the expression of the gene of interest (GOI) and the housekeeping (HK) gene was calculated according to the expression: $2^{-(\Delta \mathrm{CtGOI}-\mathrm{HK})}$ (Dauelsberg et al. 2011). Then, gene expression levels were normalized to the average value of the treatment with less gene expression. Data presented here were normalized, using AtSAND (AT2G28390) amplification as the housekeeping gene (Czechowski et al. 2005). Primer pairs used in this study were designed with Primer 3 software (Koressaar and Remm 2007; Untergasser et al. 2012) and were confirmed with Primer-BLAST (National Center for Biotechnology Information). Sequences of all primers and their references (if applicable) are listed in Supplementary Table S1. In all cases, the reaction specificities were tested with melt gradient dissociation curves and $2 \%$ agarose electrophoresis gels of each PCR product. All experiments were performed with five biological and two technical replicates. One-way ANOVA and a Student's $t$ test were carried out for each timepoint independently.

\section{Construction and phenotypic evaluation}

of a nonmotile mutant strain of $P$. phytofirmans.

The $5^{\prime}$ and $3^{\prime}$ ends of the fliA gene sequence from $P$. phytofirmans $\mathrm{PsJN}$, the gentamicin $3^{\prime}$-acetyltransferase gene sequence of pBS1 plasmid (Bronstein et al. 2005), the aminoglycoside 3 '-phosphotransferase gene sequence, and the pUC replication origin of plasmid pCR2.1-TOPO (Invitrogen) were amplified by PCR, using primer pairs FliA1Fw-FliA1Rv, FliA2Fw-FliA2Rv, GmFw-GmRv, KmFw-KmRv, and OriFwOriRv (Supplementary Table S2), respectively, and were ligated in a single-reaction method for assembling multiple overlapping DNA molecules (Gibson et al. 2009), to generate suicidal plasmid pMut-fliA. Then, this plasmid was electroporated in $P$. phytofirmans PsJN to obtain a two-recombination event, generating a replacement of the functional fliA gene by aminoglycoside 3'-phosphotransferase gene, which confers kanamycin resistance (Supplementary Fig. S3A). Accordingly, the $P$. phytofirmans fliA mutant was selected on Luria Bertani agar containing $50 \mu \mathrm{g}$ of kanamycin per milliter. Correct insertions in the mutant strain were confirmed by sensitivity to gentamycin, PCR, and sequencing. Also a growth curve in $5 \mathrm{mM}$ glucose of PsJN $\Delta f$ liA and the wild-type strain was carried out (Supplementary Fig. S4). To evaluate swimming motility the wild-type strain (PsJN) and its fliA mutant derivative (PsJN $\Delta f l i A$ ) were grown to stationary phase and $1 \mu \mathrm{l}$ of initial inoculum was placed onto plates containing minimal medium, $10 \mathrm{mM}$ fructose, and $0.25 \%$ of agar. Five days after incubation at $30^{\circ} \mathrm{C}$, colony phenotypes were photographed. The assay was done in triplicate. In order to assess the biofilm production of strain PsJN and PsJN $\Delta f l i A$, they were grown $72 \mathrm{~h}$ in microplates containing $50 \mathrm{mM}$ mannitol. Biofilms were incubated with $0.1 \%$ (wt/vol) of crystal violet dye for $30 \mathrm{~min}$, after washing with abundant water. Dry biofilms were exposed to absolute ethanol and, after $30 \mathrm{~min}$, solutions were measured through absorbance at $600 \mathrm{~nm}$ by spectrophotometry. Biofilm formation was normalized by the growth of each strain $\left(\mathrm{OD}_{600}\right)$. Five independent experiments were performed.

\section{SA extraction and quantitation.}

Three pools of $0.5 \mathrm{~g}$ of $A$. thaliana plants (13 DAS) cocultivated with or without $P$. phytofirmans PsJN in the same conditions as plants used for the qRT-PCR analysis were harvested before DC3000 infection (0 hpi) and also 24 and 48 hpi. Free and total SA (the sum of free and glycosylated SA) were extracted and were quantified as described by Verberne et al.
(2002). The SA extracts were measured by high-pressure liquid chromatography (Waters Alliance, Milford, MA), coupled to a fluorescence detector and using an Atlantis T3 column (silicabased column, $250 \times 4.6 \mathrm{~mm}$, reversed-phase $\mathrm{C} 18$ ).

\section{ACKNOWLEDGMENTS}

We thank M. J. Poupin for her valuable scientific discussion regarding this work and P. Figueroa (Instituto de Ciencias Biológicas, Universidad de Talca, Chile) for providing seeds of the coil-1 mutant line. Funding was provided by grants FONDECYT 1110850 and 3140033, the Center of Applied Ecology and Sustainability (CAPES FB-002-2014), and the Millennium Nucleus Center for Plant Systems and Synthetic Biology (NC130030). T. Timmermann was supported by a Ph.D. fellowship from the National Commission for Science and Technology, CONICYT, Chile. T. Timmermann participated in all major stages of this investigation, from conception, design, execution, analyses, and data interpretation. She also contributed to writing the manuscript. G. Armijo contributed to the design and execution of the experiments. She also participated in data processing, analysis, and discussion of relevant results. R. Donoso produced $P$. phytofirmans-derived mutant PsJN $\Delta$ fliA. He also contributed to the design of experiments involving this mutant and discussion of the results. $\mathrm{He}$ wrote the relevant methods and contributed to interpretation of these results. A. Seguel performed extraction and determination of salicylic acid concentration within $A$. thaliana tissues by high-pressure liquid chromatography. He wrote the relevant methods and contributed to interpretation of these results. L. Holuigue contributed to the design of some experiments, analysis, and discussion of relevant results. She also critically revised the manuscript to obtain the final version. B. González contributed to the design of some experiments and manuscript preparation, including critical revisions to obtain the final version. He has coordinated general approval of the final version.

\section{LITERATURE CITED}

Ait Barka, E., Gognies, S., Nowak, J., Audran, J. C., and Belarbi, A. 2002. Inhibitory effect of endophyte bacteria on Botrytis cinerea and its influence to promote the grapevine growth. Biol. Control 24: 135-42.

Ait Barka, E., Nowak, J., and Clément, C. 2006. Enhancement of chilling resistance of inoculated grapevine plantlets with a plant growth-promoting rhizobacterium, Burkholderia phytofirmans strain PsJN. Appl. Environ. Microbiol. 72:7246-7252.

Alonso, J. M., Hirayama, T., Roman, G., Nourizadeh, S., and Ecker, J. R. 1999. EIN2, a bifunctional transducer of ethylene and stress responses in Arabidopsis. Science 284:2148-2152.

Anderson, J. K., Smith, T. G., and Hoover, T. R. 2010. Sense and sensibility: Flagellum-mediated gene regulation. Trends Microbiol. 18:30-37.

Asai, S., Rallapalli, G., Piquerez, S. J. M., Caillaud, M. C., Furzer, O. J., Ishaque, N., Wirthmueller, L., Fabro, G., Shirasu, K., and Jones, J. D. G. 2014. Expression profiling during Arabidopsis/downy mildew interaction reveals a highly-expressed effector that attenuates responses to salicylic acid. PLoS Pathog. 10:e1004443.

Babalola, O. O. 2010. Beneficial bacteria of agricultural importance. Biotechnol. Lett. 32:1559-1570.

Bais, H. P., Weir, T. L., Perry, L. G., Gilroy, S., and Vivanco, J. M. 2006. The role of root exudates in rhizosphere interactions with plants and other organisms. Annu. Rev. Plant Biol. 57:233-266.

Beneduzi, A., Ambrosini, A., and Passaglia, L. M. 2012. Plant growthpromoting rhizobacteria (PGPR): Their potential as antagonists and biocontrol agents. Genet. Mol. Biol. 35 (4 (suppl)):1044-1051.

Bhattacharyya, P. N., and Jha, D. K. 2012. Plant growth-promoting rhizobacteria (PGPR): Emergence in agriculture. World J. Microbiol. Biotechnol. 28:1327-1350.

Blanco, F., Salinas, P., Cecchini, N. M., Jordana, X., Van Hummelen, P., Álvarez, M. E., and Holuigue, L. 2009. Early genomic responses to salicylic acid in Arabidopsis. Plant Mol. Biol. 70:79-102.

Bordiec, S., Paquis, S., Lacroix, H., Dhondt, S., Ait Barka, E., Kauffmann, S., Jeandet, P., Mazeyrat-Gourbeyre, F., Clément, C., Baillieul, F., and Dorey, S. 2011. Comparative analysis of defence responses induced by the endophytic plant growth-promoting rhizobacterium Burkholderia phytofirmans strain PsJN and the non-host bacterium Pseudomonas syringae pv. pisi in grapevine cell suspensions. J. Exp. Bot. 62:595-603.

Boyes, D. C., Zayed, A. M., Ascenzi, R., McCaskill, A. J., Hoffman, N. E., Davis, K. R., and Görlach, J. 2001. Growth stage-based phenotypic analysis of Arabidopsis: A model for high throughput functional genomics in plants. Plant Cell 13:1499-1510. 
Bronstein, P. A., Marrichi, M., Cartinhour, S., Schneider, D. J., and DeLisa, M. P. 2005. Identification of a twin-arginine translocation system in Pseudomonas syringae pv. tomato DC3000 and its contribution to pathogenicity and fitness. J. Bacteriol. 187:8450-8461.

Caarls, L., Pieterse, C. M. J., and Van Wees, S. C. M. 2015. How salicylic acid takes transcriptional control over jasmonic acid signaling. Front. Plant Sci. 6:170.

Carvalho, L. C., Santos, S., Vilela, B. J., and Amâncio, S. 2008. Solanum lycopersicon Mill. and Nicotiana benthamiana L. under high light show distinct responses to anti-oxidative stress. J. Plant Physiol. 165:1300-1312.

Chauvin, A., Caldelari, D., Wolfender, J. L., and Farmer, E. E. 2013. Four 13-lipoxygenases contribute to rapid jasmonate synthesis in wounded Arabidopsis thaliana leaves: A role for lipoxygenase 6 in responses to long-distance wound signals. New Phytol. 197:566-575.

Chilcott, G. S., and Hughes, K. T. 2000. Coupling of flagellar gene expression to flagellar assembly in Salmonella enterica serovar typhimurium and Escherichia coli. Microbiol. Mol. Biol. Rev. 64: 694-708.

Choudhary, D. K., and Johri, B. N. 2009. Interactions of Bacillus spp. and plants-With special reference to induced systemic resistance (ISR). Microbiol. Res. 164:493-513.

Coenye, T., and Vandamme, P. 2003. Diversity and significance of Burkholderia species occupying diverse ecological niches. Environ. Microbiol. 5:719-729.

Coleman-Derr, D., and Tringe, S. G. 2014. Building the crops of tomorrow: Advantages of symbiont-based approaches to improving abiotic stress tolerance. Front. Microbiol. 5:283.

Compant, S., Duffy, B., Nowak, J., Clément, C., and Barka, E. A. 2005a. Use of plant growth-promoting bacteria for biocontrol of plant diseases: Principles, mechanisms of action, and future prospects. Appl. Environ. Microbiol. 71:4951-4959.

Compant, S., Nowak, J., Coenye, T., Clément, C., and Ait Barka, E. 2008. Diversity and occurrence of Burkholderia spp. in the natural environment. FEMS Microbiol. Rev. 32:607-626.

Compant, S., Reiter, B., Sessitsch, A., Nowak, J., Clément, C., and Ait Barka, E. 2005b. Endophytic colonization of Vitis vinifera L. by plant growth-promoting bacterium Burkholderia sp. strain PsJN. Appl. Environ. Microbiol. 71:1685-1693.

Czechowski, T., Stitt, M., Altmann, T., Udvardi, M. K., and Scheible, W.-R. 2005. Genome-wide identification and testing of superior reference genes for transcript normalization in Arabidopsis. Plant Physiol. 139: 5-17.

Dauelsberg, P., Matus, J. T., Poupin, M. J., Leiva-Ampuero, A., Godoy, F., Vega, A., and Arce-Johnson, P. 2011. Effect of pollination and fertilization on the expression of genes related to floral transition, hormone synthesis and berry development in grapevine. J. Plant Physiol. 168:1667-1674.

De Meyer, G., Audenaert, K., and Höfte, M. 1999. Pseudomonas aeruginosa 7NSK2-induced systemic resistance in tobacco depends on in planta salicylic acid accumulation but is not associated with PR1a expression. Eur. J. Plant Pathol. 105:513-7.

De Vleesschauwer, D., and Höfte, M. 2009. Rhizobacteria-induced systemic resistance. Pages 223-281 in: Advances in Botanical Research, Vol. 51. Elsevier B.V., New York.

De Vos, M., Van Zaanen, W., Koornneef, A., Korzelius, J., Dicke, M., Van Loon, L. C., and Pieterse, C. 2007. Plants under attack. Multiple interactions with insects and microbes. Plant Signal. Behav. 2:527- 529.

Donoso, R., Leiva-Novoa, P., Zúñiga, A., Timmermann, T., RecabarrenGajardo, G., and González, B. 2017. Biochemical and genetic bases of indole-3-acetic acid (auxin phytohormone) degradation by the plantgrowth-promoting rhizobacterium Paraburkholderia phytofirmans PsJN. Appl. Environ. Microbiol. 83:1-20.

Dorn, E., Hellwig, M., Reineke, W., and Knackmuss, H. J. 1974. Isolation and characterization of a 3-chlorobenzoate degrading pseudomonad. Arch. Microbiol. 99:61-70.

Eulgem, T. 2005. Regulation of the Arabidopsis defense transcriptome. Trends Plant Sci. 10:71-78.

Fernández, O., Theocharis, A., Bordiec, S., Feil, R., Jacquens, L., Clément, C., Fontaine, F., and Barka, E. A. 2012. Burkholderia phytofirmans PsJN acclimates grapevine to cold by modulating carbohydrate metabolism. Mol. Plant-Microbe Interact 25:496-504

Fu, Z. Q., and Dong, X. 2013. Systemic acquired resistance: Turning local infection into global defense. Annu. Rev. Plant Biol. 64:839-863.

Gibson, D. G., Young, L., Chuang, R.-Y., Venter, J. C., Hutchison, C. A., 3rd, and Smith, H. O. 2009. Enzymatic assembly of DNA molecules up to several hundred kilobases. Nat. Methods 6:343-345.

Glazebrook, J., Chen, W., Estes, B., Chang, H. S., Nawrath, C., Métraux, J. P., Zhu, T., and Katagiri, F. 2003. Topology of the network integrating salicylate and jasmonate signal transduction derived from global expression phenotyping. Plant J. 34:217-228.

Haas, D., and Défago, G. 2005. Biological control of soil-borne pathogens by fluorescent pseudomonads. Nat. Rev. Microbiol. 3:307-319.

Herrera-Vásquez, A., Salinas, P., and Holuigue, L. 2015. Salicylic acid and reactive oxygen species interplay in the transcriptional control of defense genes expression. Front. Plant Sci. 6:171.

Hossain, M. M., Sultana, F., Kubota, M., Koyama, H., and Hyakumachi, M. 2007. The plant growth-promoting fungus Penicillium simplicissimum GP17-2 induces resistance in Arabidopsis thaliana by activation of multiple defense signals. Plant Cell Physiol. 48:1724-1736.

Innerebner, G., Knief, C., and Vorholt, J. A. 2011. Protection of Arabidopsis thaliana against leaf-pathogenic Pseudomonas syringae by Sphingomonas strains in a controlled model system. Appl. Environ. Microbiol. 77: 3202-3210.

Jirage, D., Tootle, T. L., Reuber, T. L., Frost, L. N., Feys, B. J., Parker, J. E., Ausubel, F. M., and Glazebrook, J. 1999. Arabidopsis thaliana PAD4 encodes a lipase-like gene that is important for salicylic acid signaling. Proc. Natl. Acad. Sci. U.S.A. 96:13583-13588.

Jones, J. D., and Dangl, J. L. 2006. The plant immune system. Nature 444: 323-329.

Kim, J., Kang, Y., Choi, O., Jeong, Y., Jeong, J. E., Lim, J. Y., Kim, M., Moon, J. S., Suga, H., and Hwang, I. 2007. Regulation of polar flagellum genes is mediated by quorum sensing and FlhDC in Burkholderia glumae. Mol. Microbiol. 64:165-179.

Kloepper, J. W., Ryu, C.-M., and Zhang, S. 2004. Induced systemic resistance and promotion of plant growth by Bacillus spp. Phytopathology 94:1259-1266.

Koornneef, A., Leon-Reyes, A., Ritsema, T., Verhage, A., Den Otter, F. C., Van Loon, L. C., and Pieterse, C. M. J. 2008. Kinetics of salicylatemediated suppression of jasmonate signaling reveal a role for redox modulation. Plant Physiol. 147:1358-1368.

Koressaar, T., and Remm, M. 2007. Enhancements and modifications of primer design program Primer3. Bioinformatics 23:1289-1291.

Kurepin, L., Park, J., Lazarovits, G., and Bernards, M. 2015. Burkholderia phytofirmans-induced shoot and root growth promotion is associated with endogenous changes in plant growth hormone levels. Plant Growth Regul. 75:199-207.

Ledger, T., Rojas, S., Timmermann, T., Pinedo, I., Poupin, M. J., Garrido, T., Richter, P., Tamayo, J., and Donoso, R. 2016. Volatile-mediated effects predominate in Paraburkholderia phytofirmans growth promotion and salt stress tolerance of Arabidopsis thaliana. Front. Microbiol. 7:1838.

Ledger, T., Zúñiga, A., Kraiser, T., Dasencich, P., Donoso, R., PérezPantoja, D., and González, B. 2012. Aromatic compounds degradation plays a role in colonization of Arabidopsis thaliana and Acacia caven by Cupriavidus pinatubonensis JMP134. Anton. Leeuw. int. J. G. 101: 713-723.

León-Reyes, A., Spoel, S. H., De Lange, E. S., Abe, H., Kobayashi, M., Tsuda, S., Millenaar, F. F., Welschen, R. A., Ritsema, T., and Pieterse, C. M. 2009. Ethylene modulates the role of NONEXPRESSOR OF PATHOGENESIS-RELATED GENES1 in cross talk between salicylate and jasmonate signaling. Plant Physiol. 149:1797-1809.

Liu, L., Sonbol, F.-M., Huot, B., Gu, Y., Withers, J., Mwimba, M., Yao, J., He, S. Y., and Dong, X. 2016. Salicylic acid receptors activate jasmonic acid signalling through a non-canonical pathway to promote effectortriggered immunity. Nat. Commun. 7:13099.

Lorenzo, O., Piqueras, R., Sánchez-Serrano, J. J., and Solano, R. 2003. ETHYLENE RESPONSE FACTOR1 integrates signals from ethylene and jasmonate pathways in plant defense. Plant Cell 15:165-178.

Lugtenberg, B., and Kamilova, F. 2009. Plant-growth-promoting rhizobacteria. Annu. Rev. Microbiol. 63:541-556.

Memelink, J. 2009. Regulation of gene expression by jasmonate hormones. Phytochemistry 70:1560-1570.

Millet, Y. A., Danna, C. H., Clay, N. K., Songnuan, W., Simon, M. D., Werck-Reichhart, D., and Ausubel, F. M. 2010. Innate immune responses activated in Arabidopsis roots by microbe-associated molecular patterns. Plant Cell 22:973-990.

Miotto-Vilanova, L., Jacquard, C., Courteaux, B., Wortham, L., Michel, J., Clément, C., Barka, E. A., and Sanchez, L. 2016. Burkholderia phytofirmans PsJN confers grapevine resistance against Botrytis cinerea via a direct antimicrobial effect combined with a better resource mobilization. Front. Plant Sci. 7:1236.

Mishina, T. E., and Zeier, J. 2007. Pathogen-associated molecular pattern recognition rather than development of tissue necrosis contributes to bacterial induction of systemic acquired resistance in Arabidopsis. Plant J. 50:500-513.

Mitter, B., Petric, A., Shin, M. W., Chain, P. S., Hauberg-Lotte, L., Reinhold-Hurek, B., Nowak, J., and Sessitsch, A. 2013. Comparative 
genome analysis of Burkholderia phytofirmans PsJN reveals a wide spectrum of endophytic lifestyles based on interaction strategies with host plants. Front. Plant Sci. 4:120.

Mur, L. A. J., Kenton, P., Atzorn, R., Miersch, O., and Wasternack, C. 2006. The outcomes of concentration-specific interactions between salicylate and jasmonate signaling include synergy, antagonism, and oxidative stress leading to cell death. Plant Physiol. 140:249-262.

Murashige, T., and Skoog, F. 1962. A revised medium for rapid growth and bio assays with tobacco tissue cultures. Physiol. Plant. 15:473-97.

Naveed, M., Mitter, B., Reichenauer, T., Wieczorek, K., and Sessitsch, A. 2014. Increased drought stress resilience of maize through endophytic colonization by Burkholderia phytofirmans PsJN and Enterobacter sp. FD17. Environ. Exp. Bot. 97:30-9.

Naznin, H. A., Kiyohara, D., Kimura, M., Miyazawa, M., Shimizu, M., and Hyakumachi, M. 2014. Systemic resistance induced by volatile organic compounds emitted by plant growth-promoting fungi in Arabidopsis thaliana. PLoS One 9:e86882.

Niu, D.-D., Liu, H.-X., Jiang, C.-H., Wang, Y.-P., Wang, Q.-Y., Jin, H.-L., and Guo, J.-H. 2011. The plant growth-promoting rhizobacterium Bacillus cereus AR156 induces systemic resistance in Arabidopsis thaliana by simultaneously activating salicylate- and jasmonate/ethylenedependent signaling pathways. Mol. Plant-Microbe Interact 24:533-542.

Nowak, J., Asiedu, S. K., Bensalim, S., Richards, J., Stewart, A., Smith, C., Stevens, D., and Sturz, A. V. 1998. From laboratory to applications: Challenges and progress with in vitro dual cultures of potato and beneficial bacteria. Plant Cell Tissue Organ Cult. 52:97-103.

Park, J. H., Halitschke, R., Kim, H. B., Baldwin, I. T., Feldmann, K. A., and Feyereisen, R. 2002. A knock-out mutation in allene oxide synthase results in male sterility and defective wound signal transduction in Arabidopsis due to a block in jasmonic acid biosynthesis. Plant J. 31: $1-12$

Penninckx, I. A., Eggermont, K., Terras, F. R., Thomma, B. P., De Samblanx, G. W., Buchala, A., Métraux, J. P., Manners, J. M., and Broekaert, W. F. 1996. Pathogen-induced systemic activation of a plant defensin gene in Arabidopsis follows a salicylic acid-independent pathway. Plant Cell 8:2309-2323.

Pieterse, C. M., Leon-Reyes, A., Van der Ent, S., and Van Wees, S. C. 2009 Networking by small-molecule hormones in plant immunity. Nat. Chem. Biol. 5:308-316.

Pieterse, C. M., Van der Does, D., Zamioudis, C., Leon-Reyes, A., and Van Wees, S. C. 2012. Hormonal modulation of plant immunity. Annu. Rev. Cell Dev. Biol. 28:489-521.

Pieterse, C. M., Zamioudis, C., Berendsen, R. L., Weller, D. M., Van Wees, S. C., and Bakker, P. A. 2014. Induced systemic resistance by beneficial microbes. Annu. Rev. Phytopathol. 52:347-375.

Pineda, A., Zheng, S.-J., van Loon, J. J., Pieterse, C. M., and Dicke, M. 2010. Helping plants to deal with insects: The role of beneficial soilborne microbes. Trends Plant Sci. 15:507-514

Pinedo, I., Ledger, T., Greve, M., and Poupin, M. J. 2015. Burkholderia phytofirmans PsJN induces long-term metabolic and transcriptional changes involved in Arabidopsis thaliana salt tolerance. Front. Plant Sci. 6:466

Poupin, M. J., Greve, M., Carmona, V., and Pinedo, I. 2016. A complex molecular interplay of auxin and ethylene signaling pathways is involved in Arabidopsis growth promotion by Burkholderia phytofirmans PsJN. Front. Plant Sci. 7:492

Poupin, M. J., Timmermann, T., Vega, A., Zuñiga, A., and González, B. 2013. Effects of the plant growth-promoting bacterium Burkholderia phytofirmans PsJN throughout the life cycle of Arabidopsis thaliana. PLoS One 8:e69435.

R Development Core Team. 2011. A language and environment for statistical computing version 3.1.1. R Foundation for Statistical Computing. Vienna. Austria.

Ran, L. X., van Loon, L. C., and Bakker, P. A. H. M. 2005. No role for bacterially produced salicylic acid in rhizobacterial induction of systemic resistance in Arabidopsis. Phytopathology 95:1349-1355.

Rudrappa, T., Biedrzycki, M. L., Kunjeti, S. G., Donofrio, N. M., Czymmek, K. J., Paré, P. W., and Bais, H. P. 2010. The rhizobacterial elicitor acetoin induces systemic resistance in Arabidopsis thaliana. Commun. Integr. Biol. 3:130-138.

Ryals, J. A., Neuenschwander, U. H., Willits, M. G., Molina, A., Steiner, H.-Y., and Hunt, M. D. 1996. Systemic acquired resistance. Plant Cell 8: 1809-1819.

Saldías, M. S., Lamothe, J., Wu, R., and Valvano, M. A. 2008. Burkholderia cenocepacia requires the RpoN sigma factor for biofilm formation and intracellular trafficking within macrophages. Infect. Immun. 76:1059-1067.

Sawana, A., Adeolu, M., and Gupta, R. S. 2014. Molecular signatures and phylogenomic analysis of the genus Burkholderia: Proposal for division of this genus into the emended genus Burkholderia containing pathogenic organisms and a new genus Paraburkholderia gen. nov. harboring environmental species. Front. Genet. 5:429.

Schwessinger, B., and Zipfel, C. 2008. News from the frontline: Recent insights into PAMP-triggered immunity in plants. Curr. Opin. Plant Biol. 11:389-395.

Senthil-Kumar, M., and Mysore, K. S. 2013. Nonhost resistance against bacterial pathogens: Retrospectives and prospects. Annu. Rev. Phytopathol. 51:407-427.

Sessitsch, A., Coenye, T., Sturz, A. V., Vandamme, P., Barka, E. A., Salles, J. F., Van Elsas, J. D., Faure, D., Reiter, B., Glick, B. R., Wang-Pruski, G., and Nowak, J. 2005. Burkholderia phytofirmans sp. nov., a novel plant-associated bacterium with plant-beneficial properties. Int. J. Syst. Evol. Microbiol. 55:1187-1192.

Spoel, S. H., Koornneef, A., Claessens, S. M., Korzelius, J. P., Van Pelt, J. A., Mueller, M. J., Buchala, A. J., Métraux, J.-P., Brown, R., Kazan, K., Van Loon, L. C., Dong, X., and Pieterse, C. M. 2003. NPR1 modulates cross-talk between salicylate- and jasmonate-dependent defense pathways through a novel function in the cytosol. Plant Cell 15 760-770

Strawn, M. A., Marr, S. K., Inoue, K., Inada, N., Zubieta, C., and Wildermuth, M. C. 2007. Arabidopsis isochorismate synthase functional in pathogen-induced salicylate biosynthesis exhibits properties consistent with a role in diverse stress responses. J. Biol. Chem. 282: 5919-5933.

Su, F., Jacquard, C., Villaume, S., Michel, J., Rabenoelina, F., Clément, C., Barka, E. A., Dhondt-Cordelier, S., and Vaillant-Gaveau, N. 2015. Burkholderia phytofirmans PsJN reduces impact of freezing temperatures on photosynthesis in Arabidopsis thaliana. Front. Plant Sci. 6:810

Theocharis, A., Bordiec, S., Fernandez, O., Paquis, S., Dhondt-Cordelier, S., Baillieul, F., Clément, C., and Barka, E. A. 2012. Burkholderia phytofirmans PsJN primes Vitis vinifera L. and confers a better tolerance to low nonfreezing temperatures. Mol. Plant-Microbe Interact 25:241-249.

Thilmony, R., Underwood, W., and He, S. Y. 2006. Genome-wide transcriptional analysis of the Arabidopsis thaliana interaction with the plant pathogen Pseudomonas syringae pv. tomato DC3000 and the human pathogen Escherichia coli O157:H7. Plant J. 46:34-53.

Trdá, L., Fernandez, O., Boutrot, F., Héloir, M. C., Kelloniemi, J., Daire, X., Adrian, M., Clément, C., Zipfel, C., Dorey, S., and Poinssot, B. 2014. The grapevine flagellin receptor VvFLS2 differentially recognizes flagellin-derived epitopes from the endophytic growth-promoting bacterium Burkholderia phytofirmans and plant pathogenic bacteria. New Phytol. 201:1371-1384.

Tsuda, K., Sato, M., Stoddard, T., Glazebrook, J., and Katagiri, F. 2009. Network properties of robust immunity in plants. PLoS Genet. 5: e1000772.

Tunpiboonsak, S., Mongkolrob, R., Kitudomsub, K., Thanwatanaying, P., Kiettipirodom, W., Tungboontina, Y., and Tungpradabkul, S. 2010. Role of a Burkholderia pseudomallei polyphosphate kinase in an oxidative stress response, motilities, and biofilm formation. J. Microbiol. 48:63-70.

Untergasser, A., Cutcutache, I., Koressaar, T., Ye, J., Faircloth, B. C., Remm, M., and Rozen, S. G. 2012. Primer3-New capabilities and interfaces. Nucleic Acids Res. 40:e115.

Uquillas, C., Letelier, I., Blanco, F., Jordana, X., and Holuigue, L. 2004 NPR1-independent activation of immediate early salicylic acidresponsive genes in Arabidopsis. Mol. Plant-Microbe Interact 17:34-42.

Van der Does, D., Leon-Reyes, A., Koornneef, A., Van Verk, M. C., Rodenburg, N., Pauwels, L., Goossens, A., Körbes, A. P., Memelink, J., Ritsema, T., Van Wees, S. C., and Pieterse, C. M. 2013. Salicylic acid suppresses jasmonic acid signaling downstream of SCFCOI1-JAZ by targeting GCC promoter motifs via transcription factor ORA59. Plant Cell 25:744-761.

Van der Ent, S., Van Hulten, M., Pozo, M. J., Czechowski, T., Udvardi, M. K., Pieterse, C. M., and Ton, J. 2009. Priming of plant innate immunity by rhizobacteria and $\beta$-aminobutyric acid: Differences and similarities in regulation. New Phytol. 183:419-431.

van Hulten, M., Pelser, M., van Loon, L. C., Pieterse, C. M., and Ton, J. 2006. Costs and benefits of priming for defense in Arabidopsis. Proc. Natl. Acad. Sci. U.S.A. 103:5602-5607.

van Loon, L. C. 2007. Plant responses to plant growth-promoting rhizobacteria. Eur. J. Plant Pathol. 119:243-54.

van Loon, L. C., Bakker, P. A., and Pieterse, C. M. 1998. Systemic resistance induced by rhizosphere bacteria. Annu. Rev. Phytopathol. 36 453-483.

van Loon, L. C., Rep, M., and Pieterse, C. M. J. 2006. Significance of inducible defense-related proteins in infected plants. Annu. Rev. Phytopathol. 44: $135-162$. 
Van Wees, S. C., Van der Ent, S., and Pieterse, C. M. 2008. Plant immune responses triggered by beneficial microbes. Curr. Opin. Plant Biol. 11: 443-448.

Verberne, M. C., Brouwer, N., Delbianco, F., Linthorst, H. J. M., Bol, J. F., and Verpoorte, R. 2002. Method for the extraction of the volatile compound salicylic acid from tobacco leaf material. Phytochem. Anal. 13:45-50.

Vlot, A. C., Dempsey, D. A., and Klessig, D. F. 2009. Salicylic acid, a multifaceted hormone to combat disease. Annu. Rev. Phytopathol. 47: 177-206.

Vos, I., Pieterse, C., and Van Wees, S. 2013. Costs and benefits of hormoneregulated plant defences. Plant Pathol. 62:43-55.

Wang, B., Mei, C., and Seiler, J. R. 2015. Early growth promotion and leaf level physiology changes in Burkholderia phytofirmans strain PsJN inoculated switchgrass. Plant Physiol. Biochem. 86:16-23.

Weller, D. M., Mavrodi, D. V., van Pelt, J. A., Pieterse, C. M., van Loon, L. C., and Bakker, P. A. 2012. Induced systemic resistance in Arabidopsis thaliana against Pseudomonas syringae pv. tomato by 2,4-diacetylphloroglucinol-producing Pseudomonas fluorescens. Phytopathology 102:403-412.
Whalen, M. C., Innes, R. W., Bent, A. F., and Staskawicz, B. J. 1991 Identification of Pseudomonas syringae pathogens of Arabidopsis and a bacterial locus determining avirulence on both Arabidopsis and soybean. Plant Cell 3:49-59.

Wildermuth, M. C., Dewdney, J., Wu, G., and Ausubel, F. M. 2001. Isochorismate synthase is required to synthesize salicylic acid for plant defence. Nature 414:562-565.

Xie, D.-X., Feys, B. F., James, S., Nieto-Rostro, M., and Turner, J. G. 1998 COI1: An Arabidopsis gene required for jasmonate-regulated defense and fertility. Science 280:1091-1094.

Xin, X.-F., and He, S. Y. 2013. Pseudomonas syringae pv. tomato DC3000: A model pathogen for probing disease susceptibility and hormone signaling in plants. Annu. Rev. Phytopathol. 51:473-498.

Yang, J., Kloepper, J. W., and Ryu, C.-M. 2009. Rhizosphere bacteria help plants tolerate abiotic stress. Trends Plant Sci. 14:1-4.

Zúñiga, A., Poupin, M. J., Donoso, R., Ledger, T., Guiliani, N., Gutiérrez, R. A., and González, B. 2013. Quorum sensing and indole-3-acetic acid degradation play a role in colonization and plant growth promotion of Arabidopsis thaliana by Burkholderia phytofirmans PsJN. Mol. PlantMicrobe Interact 26:546-553. 